\title{
CONDICIONAMENTOS MECÂNICOS DE MUDAS DE TOMATEIRO (Lycopersicon esculentum Mill.)
}

\author{
JOSÉ EDUARDO BOVI \\ Engenheiro Agrônomo
}

Orientador: Prof. Dr. KEIGO MINAMI

Dissertaçẵo apresentada à Escola Superior de Agricultura "Luiz de Queiroz", da Universidade de Săo Paulo, para obtenção do titulo de Mestre em Agronomia, Área de Concentração: Fitotecnia.

P IR A C I C A B A

Estado de São Paulo - Brasil

Agosto - 1996 
Dados Internacionais de Catalogaçāo na Publicação (CIP)

DIVISÃO DE BIBLIOTECA E DOCUMENTAÇÂO - Campus “Luiz de Queiroz"/USP

Bovi, José Eduardo

Condicionamentos mecânicos de mudas de tomateiro (Lycopersicon esculentum Mill.) / José Eduardo Bovi. - - Piracicaba, 1996.

54p. : il.

Dissertação (mestrado) - - Escola Superior de Agricultura Luiz de Queiroz, 1996.

Bibliografia.

1. Tomate - Muda - Condicionamento I. Título

CDD 635.642 


\title{
CONDICIONAMENTOS MECÂNICOS DE MUDAS DE TOMATEIRO
} (Lycopersicon esculentum Mill.)

\author{
JOSÉ EDUARDO BOVI
}

Aprovado em: 07.10 .96

Comissão julgadora:

Prof. Dr. Keigo Minani

ESALQ/USP

Prof. Dr. João Tessarioli Neto

ESALQ/USP

Prof. Dr. Paulo Spindola Trani

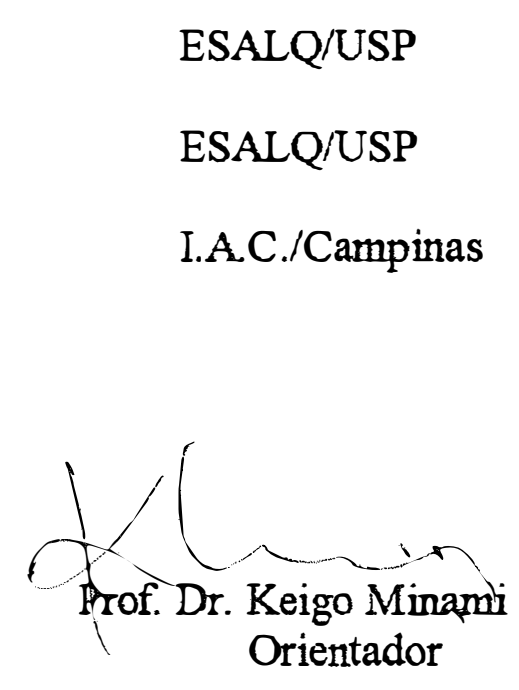


Aos meus pais Eugênio e Anna Maria, e aos sogros Olimpio e Marianina, dedico.

Às minhas filhas Cyntia e Ana Carolina e à minha querida esposa Maria Lucia, ofereço. 


\section{AGRADECIMENTOS}

- Aos Professores Drs. Keigo Minami e João Tessarioli Neto pela oportunidade e orientação;

- Ao Marcelo Corrêa Alves, Analista de Sistemas do Centro de Informática na Agricultura - Prefeitura do Campus "Luiz de Querioz" - (CIAGRI - PCLQ/USP) Piracicaba, pela orientação referente às análises estatísticas deste trabalho;

- Ao Prof. Dr. Carlos Tadeu dos Santos Dias, do Departamento de Matemática e Estatística da Escola Superior de Agricultura "Luiz de Queiroz" (ESALQ - USP), pela orientação na interpretação das análises estatísticas;

- À Escola Superior de Agricultura "Luiz de Querioz" e ao Departamento de Horticultura, por ter me recebido como aluno de pós-graduação;

- Aos colegas da Casa da Agricultura e Delegacia Agrícola de Piracicaba pelo apoio e incentivo;

- Aos dirigentes e colegas da Coordenadoria de Assistência Técnica Integral - CATI, pela oportunidade;

- Aos amigos dos cursos de pós-graduação da ESALQ-USP, "Amigos para sempre!";

- A todos que direta ou indiretamente contribuiram para a realização deste projeto de pesquisa. 


\section{SUMÁRIO}

LISTA DE FIGURAS.................................................................................... Página

LISTA DE TABELAS....................................................................... IV

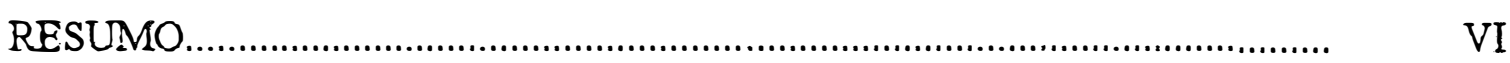

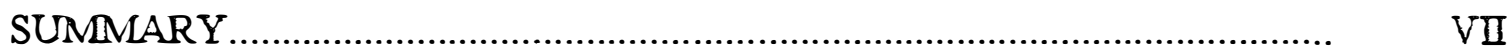

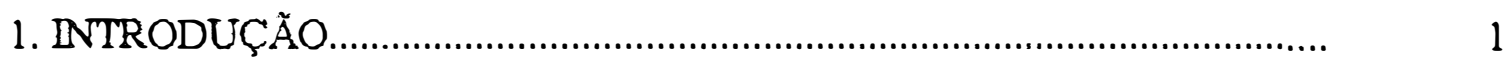

2. REVISÃO DE LITERATURA...............................................................

2.1. Condicionamentos Mecânicos................................................................ 3

2.2. Respostas das Plantas..........................................................................

2.3. Época de Aplicação.................................................................................

2.4. Hormônios Envolvidos........................................................................ 10

2.5. Periodos de Efeitos dos Condicionamentos............................................... 11

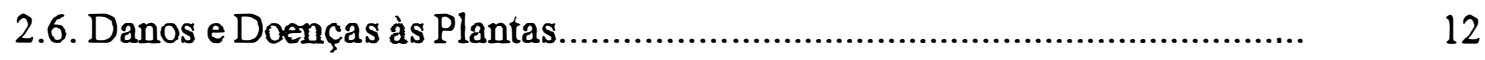

3. MATERIAL E MÉTODOS................................................................

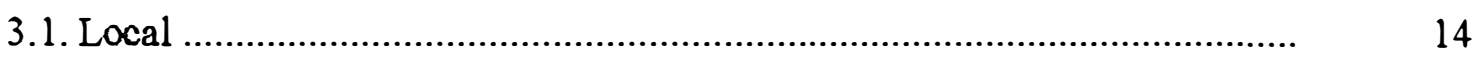

3.2. Produção de Mudas.................................................................................

3.2.1. Delineamento experimental........................................................ 14

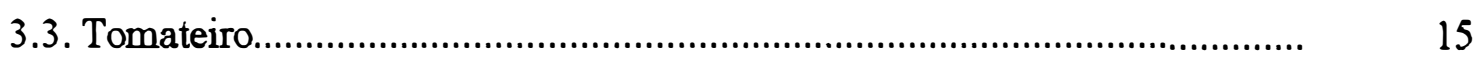

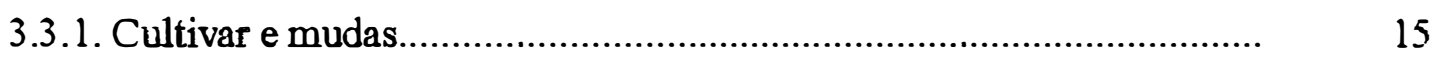

3.3.2. Substrato, Preparo das Bandejas e Semeadura................................... 15

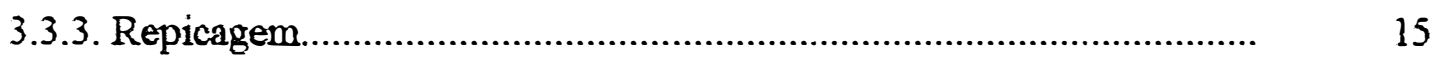

3.3.4. Tratos culturais ........................................................................... 16

3.3.5. Tratamentos Condicionadores........................................................ 16

3.4. Experimento de Campo........................................................................ 18

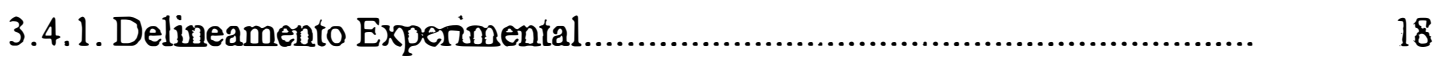

3.4.2. Transplante............................................................................ 19

3.4.3. Tratos Culturais no Campo.............................................................. 19

3.4.4. Desbrotas e Condução....................................................................... 20

3.4.5. Controle de Pragas e Doenças........................................................... 20

3.4.6. Eliminaçăo de Plantas......................................................................... 21 
3.5. Parâmetros Avaliados....................................................................... 22

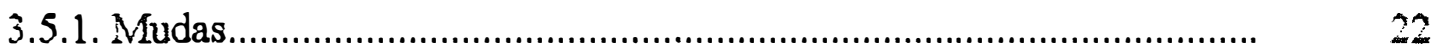

3.5.2. Pegamento das mudas............................................................... 22

3.5.3. Plantas com dez dias de transplante................................................. 22

3.5.4. Plantas aos vinte e trinta dias apos o transplante................................ 23

3.5.5. Avaliação do florescimento..............................................................

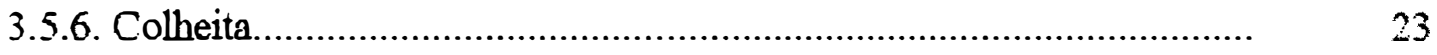

3.5.7. Altura Final das Plantas................................................................ 24

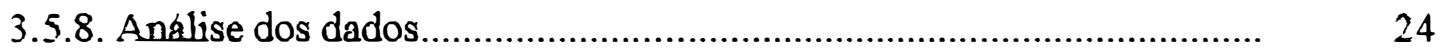

4. RESULTADOS E DISCUSSĂO.......................................................... 25

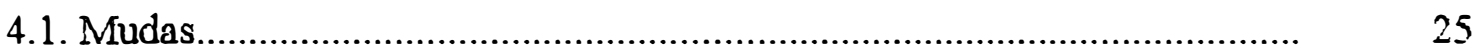

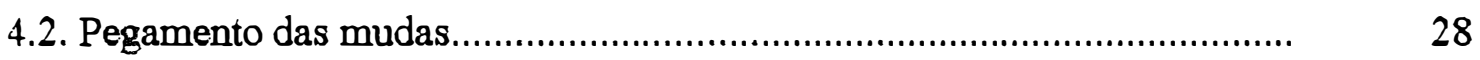

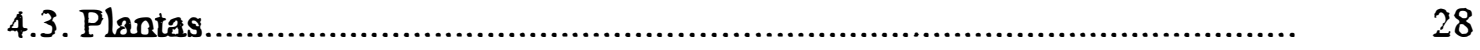

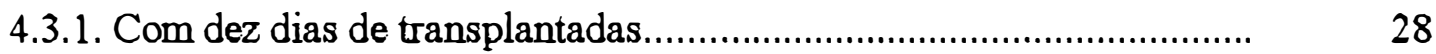

4.3.2. Parte áerea aos dez, vinte e trinta dias após o transplante.................... $\quad 30$

4.3.3. Avaliação Florescimento................................................................. 33

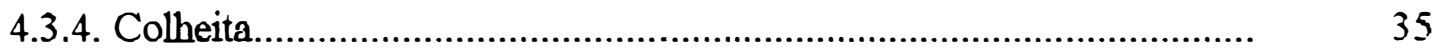

4.3.5. Altura final das plantas e Comprimento do $2^{\circ}$. Internódio................... 41

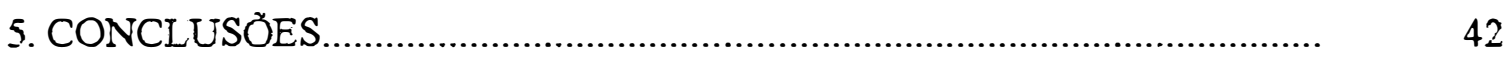

REFERĖNCIAS BIBLIOGRAFICAS..................................................... 44

APÊNDICE 


\section{LISTA DE FIGURAS}

Página

FIGURA 1. Iustração do tratamento ventilaçăo..................................................... 17

FIGURA. 2. Ilustraçăo do tratamento agitaçăo..................................................... 17

FIGURA 3. Ilustraçăo do tratamento estregamento......................................... 17

FIGURA 4. Aspectos do efeito da aplicação dos tratamentos, e testemunha...... 28

FIGURA 5. Relaciona a média do número de plantas com flores abertas acumuladas aos 29 dias entre os tratamentos após o transplante 35

FIGURA 6. Relaciona a média de produção em quilos por colheita entre os tratamentos. 


\section{LISTA DE TABELAS}

TABELA 1. Área, Produção e Produtividade de tomate no Brasil e nos Principais Estados Produtores, média 1993-94 .................. 1

TABELA 2. Área, Produção e Produtividade de Tomate no Estado de São Paulo, 1990-95 ........................................................

TABELA 3. Atributos químicos do solo da área experimental na época do transplante das mudas.

TABELA 4. Pulverizações efetuadas e produtos utilizados de agosto a outubro $/ 1995$

TABELA 5. Médias das alturas e diâmetros; número de folhas; pesos das matérias secas da raiz de mudas de tomateiros com 27 dias de idade, no dia anterior ao do transplante no campo

TABELA 6. Médias dos pesos das matérias secas: da parte aérea e total, relação peso da matéria seca da parte aérea/ peso da matéria seca da raiz, relação altura/diâmetro das mudas de tomateiros com 27 dias de idade por tratamento, no dia anterior ao do transplante no campo.

TABELA 7. Médias do pesos das matérias secas da raiz, da parte aérea e total, e a relação entre o peso da matéria seca da parte aérea/peso da matéria seca da raiz das plantas por tratamento, e coeficiente de variação com dez dias após ao transplante no campo

TABELA 8. Médias das alturas em centímetros, dos diâmetros em milímetros número de folhas, peso da matéria seca da parte aérea $\mathrm{g}$, relação altura/diâmetro das mudas por tratamento com dez, dias após o transplante. 
TABELA9. Miédias das aituras em centímetros, dos diâmetros em miiimetros número de folhas, peso da matéria seca da parte aérea $\mathrm{g}$, relação altura/diâmetro das mudas por tratamento com vinte, dias após o transplante

TABELA 10. Médias das alturas em centímetros, dos diâmetros em milimetros, número de folhas, peso da matéria seca da parte aérea g, relação altura/diâmetro das mudas por tratamento com trinta, dias após o transplante

TABELA 11. Médias de Plantas Avaliadas aos 10,20 e 30 dias ............. 32

TABELA 12. Equações Polinomiais referentes as variáveis estudadas.......

TABELA 13. Média do número de plantas com flores acumuladas (CF)por tratamento, médias do número de plantas nas parcelas(NP).

TABELA 14. Médias de tratamentos das variáveis pesos de frutos comerciais, número de frutos comerciais e peso médio do fruto comercial, obtidos na colheita das parcelas de tamanho $3,2 \mathrm{~m} \times 4,0 \mathrm{~m}$, tendo como co-variável o número de plantas na parcela.

TABELA 15. Médias de tratamentos das variaiveis pesos de frutos não comerciais, número de não comerciais, média do número de plantas doentes, obtidos na colheita das parcelas de tamanho $3,2 \mathrm{~m} \times 4,0 \mathrm{~m}$, tendo como co-variável o número de plantas na parcela

TABELA 16. Médias de produção obtida, em quilos, por colheita e por tratamento

TABELA 17. Médias de produção obtida em quilos, por colheita total de produção, por tratamento

TABELA 18. Médias das produções totais nas parcelas por tratamento..... 
TABELA 19. Médias do número de plantas colhidas por vez (colheita)... 40

TABELA 20. Médias do número de plantas colhidas por vez (colheita) entre os tratamentos....................................................... 40

TABELA 21. Médias de tratamentos das variáveis altura final de plantas e comprimento do segundo intemódio em centímetros, após a última da colheita..................................................... 41

TABELA 22. Dados climatológicos referentes ao mês de Julho/95........... 50

TABELA 23. Dados climatológicos referentes ao mês de Agosto/95......... 51

TABELA 24. Dados climatológicos referentes ao mês de Setembro/95.... $\quad 52$

TABELA 25. Dados climatológicos referentes ao mês de Outubro/95....... 53

TABELA 26. Dados climatológicos referentes ao mês de Novembro/95.... 54 


\title{
CONDICIONAMENTOS MECÂNICOS DE MUUdAS DE TOMATEIRO (Ĺycopersicon escuientum Nïii.)
}

\author{
Autor: JOSÉ EDUARDO BOVI \\ Orientador: Prof. Dr. KEIGO MINAMI
}

RESUMO

Avaliou-se o efeito dos condicionamentos mecânicos ventilação, agitação e esfregamento em mudas de tomateiro do cultivar Angela Gigante I 5.100 Asgrow. As sementes foram germinadas em bandejas em estufa plástica tipo tunel alto. Os tratamentos iniciaram-se aos três dias após a germinação das sementes, duas vezes diariamente, pela manhã e à tarde, durante 25 dias, até o dia anterior ao do transplantio das mudas no campo.

As avaliações das mudas foram efetuadas antes do transplantio, e aos dez, vinte e trinta dias depois do transplantio no campo. Os parâmetros avaliados foram a altura, diâmetro, número de folhas; pesos das matérias secas da raíz, da parte aérea e total, bem como as relações peso da matéria sec da parte aérea/raiz, altura/diâmetro; florescimento, crescimento e produção de tomate.

Os tratamentos condicionadores tiveram efeito apenas nas mudas enquanto foram aplicados. Os tratamentos agitação e esfregamento apresentaram diferença entre si, e também quando foram comparados com os tratamentos ventilação e testemunha. Enquanto a ventilação e a testemunha não apresentaram diferença estatística significativa. Após o transplantio as plantas desenvolveram-se nomalmente.

Os tratamentos ventilação e esfregamento foram os que anteciparam o maior número de plantas com flores abertas 29 dias após transplantio.

A colheita e o crescimento não tiveram variação significativa entre os tratamentos e a testemunha. 


\title{
MECHANICAL CONDITIONINGS ON TOMATO SEEDLINGS
}

(Lycopersicon esculentum Mill.)

\author{
Author: JOSÉ EDUARDO BOVI \\ Adviser: Prof. Dr. KEIGO MINAMI
}

SUMMARY

The effect of eletrical fanning, shaking and brushing conditionings was evaluated in' Angela Gigante I 5.100 Asgrow' tomato seedlings. The seeds were germinated on isopor trash with adequade substract in a plastic high tunnel. The treatments began after three days of seed germination, twice a day, in the morning and in the aftemoon, for twenty-five days until the previous day of field transplanting.

Seedlings evaluations were carried out before transplantation, and at tenth, twentieth and thirtieth days on the field. The parameters evaluated were height, diameter, leaf number; matters drys weights of root, shoot and total, and the ralations between shoot matter dry weight/ root matter dry weight, height/diameter; flowering, growth and yield were also analysed.

The mechanical conditiongs have an effect on the seedlings only when they were being used. Shaking and brushing treatments presented different effects between them, and also when they were compared to eletrical fanning and to the control. While the eletrical fanning and the control did not present statistics difference. Ater transplanting plants grow normally.

Eletrical fanning and brushing treatments anticipated a larger number of plants with opened flowers 29 days after transplanting.

Harvesting and growing had no significant variation among the treatments and the control. 


\section{NTTRODUÇÃO}

O tomateiro é uma planta dicotiledônea, ordem Tubiflorae, pertencente à família Solanaceae, gènero Lycopersicon, tendo a espécie cultivada o nome de Lycopersicon esculentum Mill (Minami \& Haag, 1989).

O tomate é um alimento de baixo valor energético, rico em vitaminas e sais minerais, sendo recomendável às pessoas que necessitam de alimentos de fácil digestão, ou que tem dieta alimentar (Minami \& Haag, 1989), podendo ser utilizado cru como em conserva produzido pelas indústrias.

O tomate é um produto agricola importante na economia do pais, cultivado em quase todos os Estados e Territórios nacionais, em 1993-94, os maiores Estados produtores com sua área colhida, produção e produtividade, bem como a área do Brasil em média, foram os seguintes (Camargo Filho \& Mazzei, 1996):

Tabela 1. Área, Produção e Produtividade de Tomate no Brasil e Principais Estados Produtores, Média 1993-94

\begin{tabular}{lccc}
\hline \multicolumn{1}{c}{ Estado } & $\begin{array}{c}\text { Área } \\
\text { (hectare) }\end{array}$ & $\begin{array}{c}\text { Produção } \\
\text { (tonelada) }\end{array}$ & $\begin{array}{c}\text { Produtividade } \\
\text { (quilos/hectare) }\end{array}$ \\
\hline São Paulo & 17.415 & 857.640 & 48.413 \\
Minas Gerais & 6.098 & 291.373 & 47.782 \\
Pernambuco & 8.174 & 298.367 & 36.502 \\
Bahia & 7.106 & 232.968 & 32.785 \\
Goiás & 5.243 & 263.300 & 50.219 \\
Rio de Janeiro & 3.450 & 179.856 & 52.219 \\
Brasil & 60.482 & 2.606 .604 & 43.097 \\
Ontros & $12.696^{\circ}$ & $483.10 \hat{0}$ & 38.054 \\
\hline
\end{tabular}


No Estado de São Paulo segundo os mesmos autores a cultura de tomate rasteiro e tomate tutorado, ocupou a seguinte ärea com produção e produtividade média:

Tabela 2. Área, Produção e Produtividade de Tomate, Estado de São Paulo, 1990-95

\begin{tabular}{|c|ccc|ccc|}
\hline \multicolumn{4}{|c|}{ Tomate rasteiro } & \multicolumn{3}{c|}{ Tomate toturado } \\
\hline Ano & Área & Produção & Produtividade & Area & Produção & Produtividade \\
& (ha) & $(1.000$ t) & $($ t/ha $)$ & (ha) & $(1.000$ t) & (t/ha) \\
\hline 1990 & 8.260 & 297.400 & 36.000 & 6.505 & 281.500 & 47.500 \\
1991 & 7.620 & 301.400 & 39.600 & 8.100 & 363.800 & 44.900 \\
1992 & 7.250 & 287.120 & 39.603 & 8.280 & 427.500 & 51.630 \\
1993 & 5.690 & 237.360 & 41.715 & 10.260 & 567.800 & 55.348 \\
1994 & 6.380 & 275.480 & 43.179 & 11.700 & 608.000 & 51.966 \\
1995 & 5.490 & 279.740 & 51.001 & 11.850 & 598.870 & 50.538 \\
\hline
\end{tabular}

Fonte: Camargo Filho \& Mazzei, 1996

A cultura apresenta-se, portanto, de dois tipos, de tomate rasteiro e de tomate tutorado, sendo que neste último produz-se mudas para se efetuar transplante, e no primeiro observa-se uma tendência ao uso de mudas para transplante.

Um fator que pode afetar a produtividade é a adaptação da cultura após o transplante para o local definitivo. As mudas sendo produzidas nomalmente em locais mais protegidos, quando levadas ao campo experimentam toda sorte de fatores adversos à sua implantação o que vem interferir na produtividade e longevidade da cultura.

O objetivo do presente trabalho é avaliar o efeito de condicionamentos mecânicos aplicados em mudas de tomate durante a formação, no desenvolvimento após o transplante. 


\section{REVISÃO DE LITERATURA}

\subsection{CONDICIONAMENTOS MECÂNICOS}

Em situações de campo, as plantas experimentam condições naturais de estresse: ventos, precipitações, contatos com máquinas, implementos agricolas e com os trabalhadores, que acabam provocando distúrbios fisicos nas mesmas.

Certas práticas culturais na horticultura, como estaqueamento e amarração de plantas, desbrotas ou podas, ensacamento de mudas, derrubadas de flores ou frutos no início do desenvolvimento, constituem-se em estresses mecânicos que podem interfer no seu crescimento.

As respostas das plantas aos estresses mecânicos tem sido estudadas

recentemente com o objetivo de controlar o crescimento delas (Beyl \& Mitchell, 1977a), e o condicionamento mecânico trata do aproveitamento prático dessas respostas aos estresses mecânicos naturais, visando o controle do seu crescimento, ou melhorando determinadas características delas quanto a sua adaptação no local definitivo de seu desenvolvimento (Latimer, 1991).

Há dois tipos de condicionamento mecânico: um, em que é realizado através de operações onde as mudas são tocadas com as mãos, papeis, réguas ou outros materiais, dentro de um critério pré-estabelecido e periodicamente; e outro, onde as plantas não recebem esses contatos, recebendo efeitos vibratórios ao serem sacudidas, ou de ventos ou correntes de ar forçadas, suspensão do fomecimento de água ou nutrientes. Certos tratamentos podem combinar os dois tipos, como pulve- 
rização vigorosa das plantas ou mudas com água e agitar manualmente os recipientes de mudas individuais ou suas bandejas (Latimer, 1991).

Com a restrição ao uso de substâncias químicas para o controle do crescimento de mudas de espécies alimentícias, e como o controle através de menor disponibilidade de água e de nutrientes não tem efeito prolongado, pois com o retomo do fornecimento as plantas (ou mudas) recobram novamente o crescimento, esse problema tomou-se um desafio, e procurou-se efetuar o controle por outros meios (Latimer, 1991).

\subsection{RESPOSTAS DAS PLANTAS}

Biddington \& Dearman (1985a), estudando o escovamento das mudas de couve-flor, alface e aipo, comprovaram a diminuição do peso da matéria seca da parte aérea, diferenciando estas espécies quanto as partes que mais respondiam aos tratamentos. O teor especifico de clorofila, por unidade de peso da matéria seca do tecido, aumentou em plântulas de alface e aipo quando agitadas (sacudidas mecanicamente). O peso especifico da folha ( peso seco: área foliar), uma estimativa da densidade foliar, também aumentou em alface, aipo e couve-flor em resposta a tratamentos mecânicos de condicionamento. $O$ escovamento reduz o crescimento radicular da alface, couve-flor e aipo, embora na alface, o condicionamento mecânico reduziu menos o crescimento das raizes do que da parte aérea, resultando um aumento de razão raízes:parte aérea. Mudas novas de couve-flor e alface submetidas ao escovamento mostraram menor poder de recobrarem as condições normais do que as testemunhas, constataram Biddington \& Dearman (1985b) após estresse hídrico. Os mesmos autores em 1988, em estudos semelhantes, o escovamento diminuiu a resistencia ao frio, em couve-flor (com 21 dias de idade), submetida a $-3^{\circ}$ C por 24 horas, porém não produziu nenhum efeito na alface, e também constataram que plantas pequenas são mais sujeitas a injúrias provocadas pelo frio do que 
aquelas maiores, e que esse tratamento não deve ser aplicado às mudas com tamanhos considerados normais para o transplante.

Latimer (1991) constatou, em 4 cultivares de pepino japonês, que o grau de retardamento do crescimento devido ao escovamento, foi proporcional ao vigor e hábito de crescimento de cada cultivar. As plantas escovadas ficam menos sujeitas a rachaduras no campo, o que pode sugerir o condicionamento como meio para prepará-las para as condições adversas do local definitivo. $O$ condicionamento mecânico reduz menos o crescimento das raízes do que da parte aérea, resultando um aumento de razão raíz: parte aérea, de um em quatro cultivares de pepino (Latimer et al. 1991).

O condicionamento mecânico reduz menos o crescimento das raizes do que da parte aérea, resultando um aumento de razão raiz: parte aérea em outras espécies, conforme constatações de Latimer (1990) em brócolos, e de Johjima et al. (1992) em três de sete cultivares de tomate observados, porém não ocorrendo em ervilha, de acordo com Akers \& Mitchell (1984) e em girassol, segundo Beyl \& Mitchell (1983).

Johjima et al. (1992) verificaram que plântulas de 4 cultivares de tomate, que diferenciavam quanto ao comprimento do internódio e ao vigor, submetidas ao escovamento apresentaram respostas semelhantes ao retardamento do crescimento, enquanto que os híbridos entre esses cultivares respondiam de maneira semelhantes aos "pais maternos".

Às vezes o condicionamento mecânico pode aumentar ou diminuir a espessura do caule, porém, em geral aumentando a resistência da plântula às injurias devido a manuseios posteriores. Em pepino, as plantas escovadas ficam menos sujeitas a rachaduras no campo, o que pode sugerir o condicionamento como meio para prepará-las para as condições adversas do local definitivo (Latimer ,1991).

As plantas condicionadas geralmente apresentam-se mais verdes que as testemunhas. O teor específico de clorofila, por unidade de peso da matéria seca 
do tecido, aumentou em plântulas de tomate quando agitados (sacudidos mecanicamente), conforme observações de Mitchell et al. (1975); e em plantas esfregadas ou agitadas de berinjela (Latimer \& Mitchell, 1988). O peso específico da folha (peso da matéria seca: área foliar), uma estimativa da densidade foliar, também aumentou em tomate, de acordo com Heuchert \& Mitchell (1983), em berinjela e soja conforme observações de Latimer et al. (1986), em ervilha, conforme Akers \& Mitchell (1984). O condicionamento físico das plântulas em estufas ou casas de vegetação pode aumentar a adaptação delas às condições de campo, em parte pelo aumento do peso especifico foliar (Latimer et al. 1986).

O condicionamento pode aumentar a resistência das mudas após o transplante. A agitação ou esfregação aumenta a resistência difusa na folha e diminui a transpiração em tomateiro (Mitchell et al. 1977), sendo que a agitação produz o mesmo em soja conforme relato de Pappas \& Mitchell (1985). Mckee (1981) afirma que as plantas sujeitas ao estresse normalizam mais a transpiração em ritmo conforme a disponibilidade de água, enquanto as não sujeitas ao estresse demoram mais.

Para a escovação, a soma de proteção varia com o grau de resposta ao crescimento, por exemplo, a grande redução do caule e a maior resistência ao frio ocorreu na soja. A resistência ao frio não aumentou em tomateiro escovado diariamente por 15 dias nas plantas quando exposta a $2,5^{\circ} \mathrm{C}$ por 72 horas, segundo observou Pardossi et al. (1988). Pode acorrer que no verão, talvez, algumas espécies submetidas a condicionamento sejam mais tolerantes ao estresse hídrico e de frio, do que as não submetidas ao condicionamento.

Liptay (1985) relatou que mudas de tomateiro quando submetidas a vibrações sob correntes de ar, adaptam-se mais rapidamente no campo, não havendo diferença no peso da matéria seca em plantas após 3 semanas no campo, embora o peso da matéria seca inicial das tratadas fosse $34 \%$ menor que as não tratadas. Latimer (1990) verificou que brócolos submetido a escovamento, também mostrou 
melhor recuperação do peso da matéria seca em relação aos não tratados, após duas semanas do transplante no campo, em dois de três testes efetuados. O aumento da relação peso da matéria seca da raiz:parte aérea (Biddington \& Dearmann, 1985a, e de Latimer, 1990), a aceleração do crescimento, nas plantas sujeitas aos estresses mecânicos conforme comprovaram Mitchell et al. (1975) e Neel \& Harris (1972), não caracterizam totalmente uma resistência, porém podem aumentar a tolerância ao estresse. Latimer (1991) ainda refere-se às afirmações e sugestões de Boussiba et al. ${ }^{1}$ (1975) de que plantas sujeitas a condicionamento mecânico, levando-a a passar por um tipo de estresse fisiológico, toma-a mais tolerante a outros estresse o que também pode ser um meio para favorecer a adaptação delas no campo.

Latimer \& Berverly (1994) em pepino, abóbora e melancia comprovaram a eficiência da escovação (40 passadas/1,5 minutos duas vezes diariamente) que controlou o crescimento dessas três espécies. Estudando também o comportamento dessas espécies quanto ao condicionamento de estresse hídrico (deixando de fornecer água porém sem chegar ao ponto letal a elas), verificaram também que houve redução do crescimento nos três cultivares com redução da perda de água pelas folhas. Esse controle aumentou a subsequente proporção relativa de crescimento do pepino e da melancia em condições normais (de não estresse) após o transplante, e da abóbora e melancia sob condições de estresse de seca em relação às testemunhas, havendo redução significativa da produção de melancia, de modo que os autores sugerem que seja limitado o uso do estresse hídrico somente às espécies tolerantes à seca. O condicionamento, tanto por escovação quanto pelo estresse de umidade, foi eficiente no controle do crescimento dessas três espécies, sem contudo reduzir a tolerância a seca e a produção da cultura. Sugerem os autores que a combinação dos dois métodos pode favorecer o condicionamento, e ser possivel

\footnotetext{
${ }^{1}$ BOUSSIBA, S.; RIKIN, A. \& RICHMOND, , A.E. The role of abscisic acid in crossadaptation of tobacco plants. Plant Physiology, Rockville, 56: 337-9, 1975.
} 
produzir mudas pequenas e mais fortes, tolerantes a seca e tendo a produção final igual às testemunhas, em casa de vegetação.

Reyes \& Jennings (1994) submeteram mudas de abóbora e pepino com 3 e 4 dias de idade a temperaturas de $2,6,10$ e $15^{\circ} \mathrm{C}$, por períodos de 24,48 , 96, 144 e 192 horas, comparando os efeitos em ambas as espécies, que apresentaram respostas semelhantes, sendo sensíveis ao frio no início do crescimento com menor habilidade de recobrar o desenvolvimento, quando se restabelecia as condições normais favoráveis. Constataram um bronzeamento nas raízes das plântulas amazenadas a $10^{\circ} \mathrm{C}$, admitindo ser devido provavelmente a uma alteração na biosíntese ou oxidação de compostos fenólicos. Temperaturas baixas provocaram alterações na permeabilidade da membrana e na integridade da mesma. Para períodos inferiores a 48 horas a $2^{\circ} \mathrm{C}$, as raizes de pepino mantiveram a integridade e a capacidade de reter água e solutos; a $15^{\circ} \mathrm{C}$, as mudas reduziram o conteúdo relativo de água provavelmente por não interromper o crescimento das raizes. Acima de 48 horas de exposição, a $2^{\circ} \mathrm{C}$, as raizes perderam a integridade da membrana celular, e ocorreu a quebra do equilíbrio de ions na célula, o que pode influenciar processos enzimáticos ou meios reguladores. Constataram perdas grandes de potássio, sódio e magnésio em relação a $\mathrm{PO}_{4}{ }^{-2}, \mathrm{Cl}^{-}, \mathrm{SO}_{4}^{-2}$, em condições de temperaturas baixas. Devido alteraçōes na respiração, os substratos de energia nesses tecidos podem ser consumidos e conduzir a uma injúria irreversivel.

\section{3. ÉPOCA DE APLICAÇÃO}

A duração, frequência e o periodo de aplicação também podem afetar a redução do crescimento. Mitchell et al. (1975) constataram que mudas do cultivar Supersonic de tomateiro, quando agitadas duas vezes diariamente por 30 segundos/vez, apresentaram maior inibição do desenvolvimento, do que quando eram agitadas uma vez diariamente por 60 segundos; a redução do crescimento entretanto 
no cuitivar Rutgers, a resposta foi independente da hora do dia em que fora aplicado o tratamento (Heuchert \& Mitchell, 1983).

Em crisântemo, a resposta à redução do crescimento do caule foi maior quando a agitąão das mudas foi aplicada de manhã (Beyl \& Mitchell, 1977b), e que um tratamento de quatro minutos, quando aplicados de manhã, tiveram resultados semelhantes de redução do crescimento do caule, do que quatro tratamentos de um minuto cada um, aplicados durante o dia, sugerindo que a frequência foi menos importante que as dosagens totais aplicados no transcorrer do dia. Contudo, Piszczek \& Jerzy $(1987)^{2}$ (citado por Latimer, 1991) concluíram que a redução do comprimento do caule de mudas de tomate foi mais efetiva quando os tratamentos por agitação foram de 5 segundos, aplicados seis vezes por dia, do que uma só de 60 segundos, uma vez por dia ou de 90 segundos em três dias.

Quando apenas um tratamento de agitação é aplicado diariamente, deverá ser executado pelo periodo da manhã, pois embora a elevação do $\mathrm{CO}_{2}$ ocorra em até uma hora após, em soja, a fotossíntese é reduzida por 5 horas, devido a resistência dos estômatos (Pappas \& Mitchell, 1985).

Segundo Biddington \& Dearman (1985a), o tempo mínimo para uma aplicação diária de condicionamento é igual a 1,5 minutos, ou então de duas vezes diariamente, segundo Latimer (1990) e Latimer et al. (1991), quando se usa o escovamento como meio de condicionamento fisico.

No inverno, a agitação reduz mais o crescimento do tomate do que no verão (Heuchert \& Mitchell, 1983; Piszczek \& Jerzy ${ }^{1}, 1987$, citado por Latimer 1991); a ervilha é mais sensivel no inverno do que na primavera ou no outono (Akers \& Mitchell, 1984). Mudas de tomateiro respondem menos a agitação quando a temperatura é de $32^{\circ} \mathrm{C} /$ dia e $28^{\circ} \mathrm{C} /$ noite do que naquelas temperaturas moderadas $27^{\circ} \mathrm{C} /$ dia e $23^{\circ} \mathrm{C} /$ noite (Heuchert \& Mitchell, 1983). Os autores concluiram

\footnotetext{
${ }^{2}$ PISZCZEK, P.M. \& JERZY, M. The response of tomato (Lycopersicon esculentum Mill.) transplants to mechanical stress. Acta Agrobotânica, Warszawa, 40: 5-14, 1987.
} 
que de uma forma geral, a resposta das plantas é grande aos condicionamentos mecânicos em temperaturas menores e pouca intensidade de luz.

Mudas de tomate tem o alongamento do caule grandemente reduzido devido a agitação no verão, em condições de luz reduzida (abaixo de $17 \%$ de luz

plena) enquanto que a área foliar é afetada somente com alta luminosidade ( $44 \%$ da luz plena), conforme constataram Heuchert \& Mitchell (1983). Pappas \& Mitchell (1985) obtiveram resuitado semelhante para a soja, enquanto Heuchert \& Mitchell (1983) acharam, em equivalentes tratamentos de agitação em tomateiros, redução na área foliar de $34 \%$ durante o inverno em relação a $19 \%$ durante o verão, e com o uso de cobertura no verão, de modo que a energia solar recebida foi a mesma nas duas estações, sugerindo uma indefinida interação com outras condições de crescimento.

Geralmente com pouca intensidade de luz, a altura da planta é reduzida no verão, embora com menor efeito sobre o tamanho das folhas.

\subsection{HORMÔNIOS ENVOLVIDOS}

O condicionamento afeta o equilibrio hormonal das plântulas, particularmente a produção de hormônios da raiz (Beyl \& Mitchell 1983), o que pode afetar a suscetibilidade às doenças; as respostas a longevidade desses hormônios $\mathrm{e}$ seus impactos na vulnerabilidade às doenças são desconhecidas.

O mecanismo de resposta ainda não está esclarecido. Segundo Latimer (1991), genes estão envolvidos.

O etileno tem estado envolvido em muitas respostas de plantas e, segundo Mitchell (1977), a interação entre auxina e etileno pode ocorrer. Biddington \& Dearman (1986) constataram que em couve-flor escovadas, o etileno não aparece como responsável pelo retardamento do crescimento. Em trigo, Narayana et al. (1991), através de estresse provocado por falta de água, comprovaram que o au- 
mento de etileno é devido a rápida secagem de folhas, e não uma conseqüência do estresse devido a supressão da água às plantas. Já em cevada, o estresse provocado pela supressão da água provoca a redução do potencial osmótico das folhas, aumentando a concentração de prolina, e também a concentração de açucares a medida que decresce o potencial osmótico (Roazi et al. 1985). A redução de promotores semelhantes as giberelinas em girassol agitados (Beyl \& Mitchell, 1983) pode ser o responsável pela redução do alongamento do caule e expansão foliar. A esfregação e agitação inibem o transporte polar da auxina em caules de ervilha (Mitchell, 1977). O teor de ácido abscísico ou outros inibidores aumentou em couve-flor agitada ou esfregada (Beyl \& Mitchell, 1983), todavia, não se alterou em berinjela em 3 dias de agitação, comprovados por Latimer \& Mitchell (1988) ou por escovação em alface e couve-flor comprovada por Biddington \& Dearman (1988). Determinando-se o papel do hormônio na planta em condicionamento mecânico, pode-se ter a informação do mecanismo de resposta entre o gene de indução, controle do crescimento da planta e seu desenvolvimento.

\subsection{PERÍODOS DE EFEITOS DOS CONDICIONAMENTOS}

O condicionamento mecânico afeta o periodo de crescimento apenas durante o tempo de tratamento e cerca de três dias após, que é o periodo considerado de readaptação das mudas, sendo isso desejável no caso de mudas de transplante. Todavia, tem sido relatado longos periodos de efeitos no carmpo. Em casa de vegetação, plântulas de batata quando submetidas à agitação durante a fase vegetativa e reprodutiva tem o peso dos tubérculos diminuido, embora não diminua o número de tubérculos, fatos constatados por Akers \& Mitchell (1985). Em tomateiro, também em casa de vegetação, a agitação por duas vezes ao dia, no período de pro- 
dução de frutos, reduziu a produção em $18 \%$, mas a agitação em dias alternados não afetou a produção (Buitelaar, 1989³ , citado por Latimer, 1991).

Poucos efeitos longos tem sido esperados do condicionamento mecânico, desde que os tecidos reprodutivos não sejam tratados. A escovação de mudas de alface, somente durante o periodo de transplante, reduz o tamanho e aumenta as características de manuseio para o transplante (Wur et al. 1986), não tendo afetado o peso da cabeça e maturidade no campo; o mesmo aconteceu com brócolos condicionado com escovação ou ventos, que não teve o peso da cabeça alterado no campo, conforme constatou Latimer (1990). Pardossi et al. (1988) verificaram que tomateiros escovados e colocados antes do transplante em estufa a $9^{\circ} \mathrm{C}$, reduziram a produção inicial, porém, não a total. Tomateiros escovados e transplantados em seguida, em estufa, não tiveram nenhum efeito na produção inicial e total, podendo entretanto trazer injúrias às flores do tomateiro presentes nos últimos estágios dos tratamentos (Johjima et al. 1992); essas injúrias podem ser responsáveis pelo decréscimo da produção inicial verificada por Pardossi et al. (1988). Todavia, o cultivar de pepino Ritsurin submetido ao escovamento, teve a produção reduzida durante o periodo todo de colheita, enquanto que a produção de outros três cultivares não foi afetada, segundo observações de Latimer et al. (1991), havendo necessidade de se pesquisar melhor os efeitos longos, tanto físicos como os fisiológicos.

\subsection{DANOS E DOENÇAS Às PLANTAS}

Os danos causados às plantas também são diferentes. Assim mudas de berimjela são facilmente danificadas por atrito, (Latimer et al., 1986). Repolho e brócolos são mais facilmente danificados pela escovação do que tomate e pimenta, e a pimenta mais que o tomate no mesmo tratamento (Latimer, 1991). Em tomatei-

\footnotetext{
${ }^{3}$ BUTIELAAR, K. Tomatoes. Plant Movement can lead to a lower yield. Groenten en Fruit, Dean Haag, 44 (29):31, 1989.
} 
ros, apenas um dos cultivares dentre sete, o cultivar Dantobi-yohzu, apresentou na primeira semana de escovação danos, e os demais não apresentaram nenhum, segundo Johjima et al. (1992).

As plântulas mais jovens são mais facilmente danificadas pelo condicionamento, indicando que a época do inicio do tratamento também pode afetar a resposta da planta ao estresse.

Outro aspecto do condicionamento mecânico é o aparecimento de doenças e sua disseminação. Procedimentos como cortar, podar, fazer incisão, podem abrir portas a patógenos. Embora a escovação ainda não tenha provocado doenças, poderá, favorecê-las. No caso da presença de alguma doença, as plantas suspeitas deverão ser retiradas antes do condicionamento (Latimer, 1991); as plantas escovadas mostraram-se mais susceptiveis à doenças. Plântulas de tomateiro foram previamente inoculadas com Fusarium oxisporum e depois escovadas por 14 dias, o tempo de inoculação da doença foi diminuído em relação as testemunhas (Shawish \& Baker, 1982); observações análogas foram verificadas em plântulas de linho e ervilha, quanto às fusarioses dessas culturas. Mudas de tomate de mesmo tamanho, com incisões e escovadas por 5 dias, foram inoculadas, enraizadas e transplantadas em vasos e após 50 dias os cortes nas mudas escovadas apresentaram sintomas mais severos. Há necessidade de verificar se no caso de mudas condicionadas sem o contato do homem ou de ferramentas, como agitąão e ventos por exemplo, as plantas tomam-se mais vulneráveis às doenças.

As espécies e os cultivares da mesma espécies diferenciam entre si quanto às respostas aos tipos dos condicionamentos mecânicos, e o conhecimento dessas respostas, poderá ter utilidade no preparo de mudas tolerantes a possíveis estresses, que poderão ocorrer após o transplante. 


\section{MATERIAL E MÉTODOS}

\section{1. Local}

O experimento foi instalado na área experimental do Departamento de Horticultura da ESALQ, em Piracicaba, cujo clima é o tropical úmido, com inverno seco, Cwa, com temperatura do mês mais quente superior a $22,5^{\circ} \mathrm{C}$, segundo a classificação de Köppen, e apresentou-se durante a realização do experimento conforme as anotações relacionadas nas Tabelas 22 a 26, constantes do Apêndice, obtidas do posto meteorológico do Departamento de Física e Meteorologia da Escola Superior de Agricultura "Luiz de Queiroz", e referentes a precipitação em milímetros, porcentagem de umidade relativa, velocidade do vento em quilometros por hora; temperaturas máxima, mínima e média em graus centígrados; a evaporação em milímetros. Constou de duas fases: produção de mudas e condução no campo.

\subsection{Produção de mudas}

Para a produção de mudas e aplicação dos tratamentos condicionadores, o experimento foi conduzido em estufa tipo tunel alto.

\section{2. 1. Delineamento experimental}

A formação de mudas e aplicação dos tratamentos condicionadores o delineamento experimental foi inteiramente casualizado com quatro tratamentos e 
doze repetições, com a semeadura no dia 09/07/95 em 48 bandejas de isopor de dimensões 67 centímetros por 37,5 centímetros contendo 128 compartimentos cada uma.

\section{3. Tomateiro}

\subsection{Cultivar e mudas}

O cultivar foi o Angela Gigante I 5.100 Asgrow, tipo Santa Cruz e de crescimento indeterminado, cujas sementes foram adquiridas no comércio local; as mudas foram formadas, em bandejas, em estufa.

\subsection{2 . Substrato, Preparo das Bandejas e Semeadura}

As bandejas, em número de 48 , foram preenchidas no dia 08/07/95 com o substrato Gioplanta I, apropriado para a produção de mudas de tomateiro e produzido pela empresa Gioplanta - Comércio e Representação Agricola Ltda localizada em Monte Mor -SP.

A semeadura ocorreu no dia seguinte 09/07/95, colocando-se duas sementes por compartimentos, sendo cobertas com o próprio substrato.

\section{3. 3 . Repicagem}

A repicagem ocorreu após três dias da germinação nos dias 18 e 19/07/95, eliminando as plântulas excessivas de modo a manter apenas uma por compartimento. 


\section{3. 4 . Tratos Culturais}

As mudas receberam uma pulverizacaão com o produto Curzate $M$ mais zinco (Cymoxanil $80 \mathrm{~g} / \mathrm{kg}$, Maneb $640 \mathrm{~g} / \mathrm{kg}$, e sulfato de zinco monohidratado $20 \mathrm{~g} / \mathrm{kg}$ ) na dosagem de $4 \mathrm{~g} / 2$ litros de água no dia $11 / 08 / 95$; e uma adubação nitrogenada ( $20 \mathrm{~g}$ de sulfato de amônio/ 2 litros de água), irrigando-se as mudas com regador e logo em seguida com água, no dia 12/08/95.

A irrigação foi efetuada diariamente uma vez, com nebulizador automático, existente na própria estufa, sendo efetuada por volta das doze horas e trinta minutos.

\section{3. 5. Tratamentos Condicionadores}

Os tratamentos condicionadores foram:

I. Ventilação: cada bandeja era submetida a corrente de ar proporcionada por um ventilador doméstico portátil, na maior rotação, o que provocava ventos de velocidade de $2,8 \mathrm{~m} / \mathrm{s}$ a $50 \mathrm{~cm}$ do alvo. O vento era aplicado sobre as mudas durante dois minutos, ficando o ventilador a uma distancia de 30 centímetros da bandeja, duas vezes diariamente.

II. Agitação: cada bandeja foi colocada individualmente em agitador de laboratório (que realiza movimentos na horizontal de vai e vem), instalado na estufa plástica, colocando-o em funcionamento por cinco minutos, na menor rotação, correspondendo a 180 movimentos de ida e volta por minuto, duas vezes diariamente.

III. Esfregamento (com régua de madeira): constava da passagem da régua em movimentos de ida e volta, roçando os ponteiros das mudas sem danificálas, com 20 movimentos de ida e volta, por minuto, duas vezes diariamente.

Os tratamentos eram aplicados no periodo da manhã e à tarde. 
IV. Para as bandejas testemunhas não houve tratamento condicionador.

Para a aplicação dos tratamentos foram sorteadas bandejas, uma para cada tratamento até completar o total de doze bandejas para cada tratamento. Os tratamentos tiveram início em 21/07/95 e prolongados até 14/08/95, num total de 25 dias consecutivos e duas vezes por dia.

As Figuras de 1 a 3, ilustram os tratamentos respectivamente de ventilação, agitação, esfregamento.

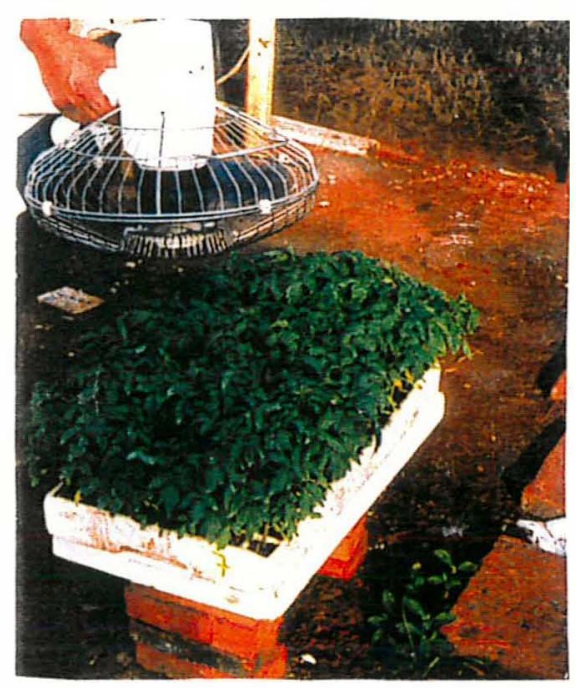

Figura 1. Ventilação

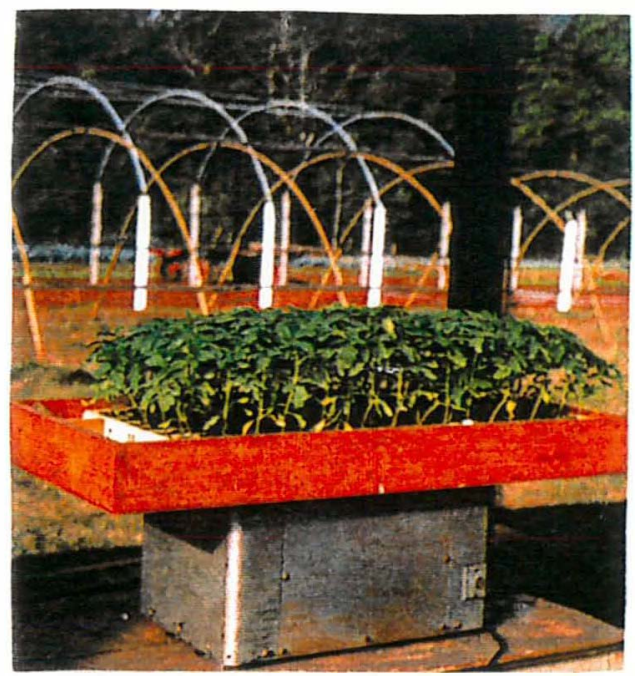

Figura 2. Agitação

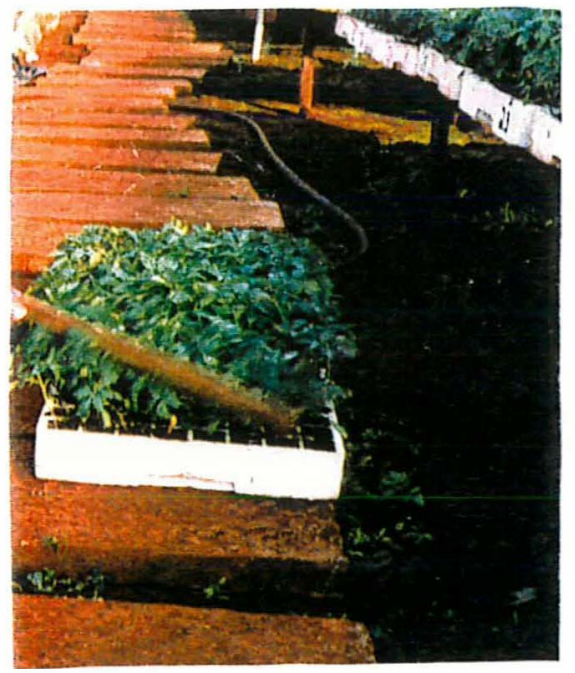

Figura 3. Esfregamento. 


\subsection{Experimento de Campo}

O experimento de campo efetuado no mesmo Departamento, em solo classificado como Terra Roxa Estruturada, com Horizonte A Moderado, Eutrófico, Textura Muito Argilosa, sendo seus atributos químicos apresentados na Tabela 3:

Tabela 3. Atributos químicos do solo da área experimental na época do transplante das mudas.

\begin{tabular}{|c|c|c|c|c|c|c|c|c|}
\hline & & & {$[-\infty+\infty$} & $\mathrm{meq} / 1 \mathrm{c}$ & $0 \mathrm{~cm}^{3}-$ & - & -1 & \\
\hline $\begin{array}{l}\mathrm{P} \mu \mathrm{g} \\
\text { Resina }\end{array}$ & $\begin{array}{c}\text { M.O. } \\
\%\end{array}$ & $\underset{\mathrm{CaCl}^{2}}{\mathrm{pH}}$ & $\mathrm{Ca}$ & $\mathrm{Mg}$ & $\mathrm{H}+\mathrm{Al}$ & $\mathrm{S}$ & $\mathrm{T}$ & $\mathrm{V} \%$ \\
\hline 78,0 & $2,6 a$ & 5,55 & $0,74 a \quad 4,81 a$ & $1,14 \mathbf{a}$ & 3,25 & 6,7 & 9,9 & 67,3 \\
\hline
\end{tabular}

Como se vê os teores são altos, com exceção dos teores de $\mathrm{H}+\mathrm{Al}$ que são baixos.

\subsubsection{Delineamento experimental}

O delineamento experimental foi em blocos casualizados, com cinco repetições, totalizando 20 parcelas, medindo 3,2 metros de largura por 4,0 metros de comprimento, sendo que foram as mudas transplantadas em linhas espaçadas de 0,8 metros (quatro linhas), e nas linhas espaçadas a 0,10 metros. Para o transplante foram sorteados os tratamentos para as parcelas em cada bloco, e para cada parcela e respectivo tratamento, as bandejas correspondentes, selecionando-se as mudas de mesmo padrão. 
Não houve necessidade de calagem, e a adubação de piantio foi de 200 gramas da fórmula 04-14-08 colocada por metro de sulco, sendo cobertos com terra.

O delineamento das parcelas no campo foi efetuado por sorteio, ficando os blocos a uma distancia de um metro entre si, não havendo separação entre as parcelas, com numeração e indicação do tratamento (condicionamento) que receberam as mudas plantadas.

Nessa área não se efetuava o plantio há aproximadamente um ano, sendo o último cultivo com a cultura da cebola. A mesma foi adequadamente arada e realizada a gradagem, feitos os sulcos para plantio, colocado fertilizantes nos sulcos e em seguida cobertos com terra, e a área sulcada novamente ao lado. A irrigação foi por aspersão. O transplante ocorreu no dia 15/08/95, e imediatamente após efetuou-se uma irrigacão, que foi repetida diariamente na primeira semana, e depois em dias alternados até condução normal com a mesma ocorrendo duas a três vezes por semana.

\section{4. 2. Transplante}

O transplante das mudas no campo ocorreu no dia 15/08/95, plantando-se as mudas nas parcelas de acordo com o tratamento e as bandejas sorteadas. $O$ transplante foi feito manualmente nos sulcos, após o mesmo a área foi adequadamente irrigada.

\section{4. 3. Tratos culturais no campo}

As mudas foram irrigadas diariamente na primeira semana após o transplante, e posteriormente essas regas foram espaçando-se até o número de 2 a 3 regas por semana. 
O controle das plantas daninhas foi efetuado manualmente e através de capinas.

As plantas foram adubadas em cobertura com a mistura de 850 gramas de sulfato de amônio com 100 gramas de cioreto de potássio, na razão de 25 gramas/planta dessa mistura, aos 15, 30 e 45 dias após o transplante.

\section{4. 4. Desbrotas e Condução}

As desbrotas ocorreram após a eliminação das plantas em excesso nas parcelas, ou seja, quando o espaçamento das plantas nas linhas passou a ser de 0,50 metros, sendo realizada em todas as parcela semanalmente, e no mesmo dia, até o final do ciclo da cultura.

Para a condução da cultura foi esticado um fio de arame na linha das mesmas, através de dois mourões, e por meio de um fio plástico amarrado no arame e numa estaca próxima a cada planta, esta era conduzida nestes plásticos. A condução das plantas foi com uma haste apenas.

\section{4. 5. Controle de pragas e doenças}

As plantas foram pulverizadas com produtos comerciais constantes da Tabela 4, com os respectivos princípios ativos e dosagens, visando o controle preventivo das pragas e doenças, visto que na área experimental do Departamento ser comum a ocorrência de vetores de virus, além de doenças comuns na cultura de tomate. 
Tabela 4. Pulverizações efetuadas e produtos utilizados de agosto a outubro/95

\begin{tabular}{|c|c|c|c|}
\hline Data & Produtos & Princípios Ativos & Dosagens \\
\hline $18 / 08$ & $\begin{array}{l}\text { Curzate } M \text { mais } \\
\text { Zinco }\end{array}$ & $\begin{array}{l}\text { Cymoxanil } 80 \mathrm{~g} / \mathrm{kg}, \text { Maneb } 640 \mathrm{~g} / \mathrm{kg} \\
\text { Sulfato de zinco } 20 \mathrm{~g} / \mathrm{kg} \text {. }\end{array}$ & $\begin{array}{l}20 \mathrm{~g} / 10 \text { litros } \\
\text { de água. }\end{array}$ \\
\hline $22 / 08$ & Lorsban $480 \mathrm{Br}$ & Chlorpyrifós $480 \mathrm{~g} / 1$ & $\begin{array}{l}15 \mathrm{ml} / 10 \mathrm{li}- \\
\text { tros de água. }\end{array}$ \\
\hline $25 / 08$ & $\begin{array}{l}\text { Daconil } \mathrm{Br}+\text { Tama- } \\
\text { ron } \mathrm{BR}\end{array}$ & $\begin{array}{l}\text { Clorotalonil } 750 \mathrm{~g} / \mathrm{kg}+\text { Metamidofós } \\
600 \mathrm{~g} / 1\end{array}$ & $\begin{array}{l}\text { 20g. mais } \\
10 \mathrm{ml} / 101 \mathrm{de} \\
\text { água. }\end{array}$ \\
\hline 03/09 & $\begin{array}{l}\text { Ridomil } 250 \mathrm{PM}+ \\
\text { Tamaron } \mathrm{Br}\end{array}$ & $\begin{array}{l}\text { Metalaxyl } 250 \mathrm{~g} / \mathrm{kg}+\text { Metamidofós } \\
600 \mathrm{~g} / 1\end{array}$ & $\begin{array}{l}30 \mathrm{~g} \text { mais } 10 \\
\mathrm{ml} / 10 \text { litros } \\
\text { dágua. }\end{array}$ \\
\hline $07 / 09$ & $\begin{array}{l}\text { Vanox } 750 \mathrm{PM}+ \\
\text { Tamaron BR }\end{array}$ & $\begin{array}{l}\text { Clorotalonil } 750 \mathrm{~g} / \mathrm{kg}+\text { Metamidofós } \\
600 \mathrm{~g} / 1\end{array}$ & $\begin{array}{l}20 \mathrm{~g} \text { mais } \\
10 \mathrm{ml} / 101 \mathrm{de} \\
\text { água }\end{array}$ \\
\hline $22 / 09$ & $\begin{array}{l}\text { Vanox } 750 \mathrm{PM} \\
\text { (clorotalonil)+ Ta- } \\
\text { maron BR }\end{array}$ & $\begin{array}{l}\text { Clorotalonil } 750 \mathrm{~g} / \mathrm{kg}+\text { Metamidofós } \\
600 \mathrm{~g} / 1\end{array}$ & $\begin{array}{l}20 \mathrm{~g} \text { mais } \\
10 \mathrm{ml} / 101 \mathrm{de} \\
\text { água }\end{array}$ \\
\hline $04 / 10$ & $\begin{array}{l}\text { Vanox } 750 \mathrm{PM} \\
\text { (Clorotalonil) }+ \\
\text { Tamaron BR }\end{array}$ & $\begin{array}{l}\text { Clorotalonil } 750 \mathrm{~g} / \mathrm{kg}+\text { Metamidofós } \\
600 \mathrm{~g} / 1\end{array}$ & $\begin{array}{l}20 \mathrm{~g} \text { mais } \\
10 \mathrm{ml} / 101 \mathrm{de} \\
\text { água. }\end{array}$ \\
\hline $12 / 10$ & $\begin{array}{l}\text { Curzate M mais } \\
\text { Zinco + Tamaron } \\
\text { BR }\end{array}$ & $\begin{array}{l}\text { Cymoxanil } 80 \mathrm{~g} / \mathrm{kg} \text {, Maneb } 640 \mathrm{~g} / \mathrm{kg} \mathrm{e} \\
\text { Sulfato de zinco } 20 \mathrm{~g} / \mathrm{kg}+\text { Meta- } \\
\text { midofös } 600 \mathrm{~g} / 1\end{array}$ & $\begin{array}{l}20 \mathrm{~g} \text { mais } \\
10 \mathrm{ml} / 101 \mathrm{de} \\
\text { água }\end{array}$ \\
\hline
\end{tabular}

\section{4. 6. Eliminação de plantas}

Após ao témino das coletas de plantas para obtenção de dados, as parcelas foram deixadas com plantas nas linhas a 0,50 centímetros umas das outras, ou seja foi eliminado o excesso de plantas nas parcelas, no dia 15/09/95. 


\section{5. Parâmetros Avallados}

\section{5. 1. Mudas}

As mudas foram amostradas com 27 dias de idade no dia anterior ao do transplante, coletando-se dez ao acaso, porém com critérios pré estabelecidos, assim: a terceira na fileira 2 , a quinta da fileira 3 , etc, em seis bandejas sorteadas de cada tratamentos. Foram lavadas cuidadosamente em água corrente para a eliminação do substrato, e avaliados a altura e o diâmetro, o número de folhas. Posteriormente identificadas individualmente e levadas à estufa a $70^{\circ} \mathrm{C}$ por mais de 72 horas até peso constante, quando foram determinados o peso da matéria seca total, peso da matéria seca do sistema radicular, e por diferença o peso matéria seca da parte aérea.

\section{5. 2. Pegamento das mudas}

Após o transplante foram efetuadas avaliações diárias para verificar o pegamento das mudas.

\section{5. 3. Plantas com dez dias de transplante}

No dia 25/08/95 foram arrancadas cuidadosamente dez mudas por parcela com critérios preestabelecidos utilizados em todas as parcelas, numeradas, e anotadas a altura (do colo da planta até a gema apical) em centímetros, o diâmetro abaixo do primeiro internódio (nó) em milímetro, o número de folhas, e lavadas separadamente para eliminar o solo das raizes, identificadas individualmente sendo levadas a estufa à $70^{\circ} \mathrm{C}$ por mais de 72 horas até peso constante, quando foram determinados o peso da matéria seca total, peso da matéria seca do sistema radicular, 
e por diferença o peso matéria seca da parte aérea em gramas. Posteriormente foram feitas as médias dessas variáveis por tratamento.

\section{5. 4. Plantas aos vinte e trinta dias após o transplante}

Nos dias 04/09/95 e 14/09/95, foram coletadas a parte aérea a partir de 1 centímetro do solo, dez plantas por parcela, com critérios também preestabelecidos utilizados igualmente para todas as parcelas, numeradas, e anotadas a altura e o diâmetro de maneira análoga a avaliação anterior, o número de folhas, identificadas individualmente e submetidas à estufa à $70^{\circ} \mathrm{C}$ por mais de 72 horas até peso constante, quando foram determinados o peso matéria seca da parte aérea, em gramas.

\section{5. 5. Avaliação do florescimento}

Em cada parcela foi observada a ántese das flores nas plantas nos dias 03/09/95, 07/09/95, 10/09/95 e 13/09/95, respectivamente aos 19, 23, 26 e 29 dias após o transplante, contando o total de plantas com flores abertas e o número de plantas em cada parcela. As contagens foram sendo acumuladas a partir da primeira avaliação.

\section{5. 6. Colhelta}

A colheita foi realizada uma vez por semana a partir de 19/10/95, durante sete semanas. A cultura foi atingida por ventos que o Posto Meteorológico do Departamento de Física e Meteorologia da ESALQ registrou com velocidade máxima de $126 \mathrm{~km}$ por hora $(35,2 \mathrm{~m} / \mathrm{s})$ aproximadamente, no dia $20 / 10 / 95$ entre 6:30 horas e 7:00 horas, além de uma intensa chuva de granizo o que provocou da- 
nos em todas as parcelas, ficando as piantas com as folhas todas perfuradas, 0 caule e os frutos marcados pelo granizo. Isso fez com que a longevidade da colheita fosse prejudicada, abreviando o ciclo da cultura, propiciando apenas sete colheitas. Foram colhidos os frutos em fase de início do processo de maturação, com a cor tendendo para o amarelo, e separados os frutos comerciais dos não comerciais, pesados e contados.

O número de plantas colhidas por parcela e por colheita foi anotado.

\section{5. 7. Altura final das plantas}

Após o término da última sernana de colheita, foram anotadas a altura medida do colo até a gema apical, e o comprimento do segundo internódio, em centímetros, de dez plantas, ao acaso, por parcela.

\section{5. 8. Análise dos dados}

Os dados foram processados e as médias foram analisados pelo Sistema de Análise Estatistica - SANEST. 


\section{RESULTADOS E DISCUSSÃO}

\section{1. Mudas}

Os condicionamentos realçaram a cor verde nas folhas, comprovada também por Mitchell et al. (1975) em tomateiros, e Latimer \& Mitchell (1988) em berinjela. Não houve danos visiveis às mudas, de certa forma coerente com o que constatou Johjima et al. (1992) que, em sete cultivares de tomate estudados e submetidos a escovamento, apenas verificou danos em um deles. Não ocorreram sintomas de doenças.

As Tabelas 5 e 6 mostram os dados referentes a altura, diâmetro, número de folhas, peso da matéria seca total, peso da matéria seca da parte aérea, peso da matéria seca da raiz, relação peso da matéria seca da parte aérea/peso da matéria seca da raiz, e relação altura/diâmetro das mudas com 27 dias de idade, no dia anterior ao do transplante no campo. A ordem decrescente de valores numéricos da altura da muda por tratamento foi testemunha, ventilação, agitação e esfregamento, sendo que ocorreram diferenças significativas para os dois últimos entre si e em relação aos dois primeiros, enquanto estes apenas apresentaram diferenças em valores numéricos. Os tratamentos condicionadores diminuiram a altura das mudas, sendo a redução menor para as raízes, resultados que coincidem com os obtidos por Johjima et al. (1992) para o escovamento em tomateiros, e com os de Latimer (1990) para a agitação em brócolos. Para o diâmetro das mudas, a ordem descrescente de valores numéricos foi esfregamento, agitação, ventilação e testemunha, exatamente o inverso da altura, com diferenças significativas para os tratamentos testemunha e esfregamento, entre si e em relação aos demais. Estes resultados diferem dos de Johjima et al. (1992) que os encontrou apenas em um cultivar dentre os sete estudados de tomateiros. Quanto a relação dos pesos das matérias secas da parte aérea/ da raiz, o esfregamento diferenciou apenas da agitação, e não diferenci- 
ando-se dos demais, enquanto que a testemunha, a agitação e ventilação não apresentaram diferenças significativas, o mesmo obtido por Jojima et al. (1992) para o tratamento escovamento. Para a relação altura/ diâmetro das mudas os tratamentos apresentaram diferenças significativas, ficando em ordem decrescente de valores para testemunha, ventilação, agitação e esfregamento, o que demonstra que a redução da altura e o aumento do diâmetro variam conforme a modalidade do tratamento, concordando com Latimer et al.(1991), em pepino. Quanto as variáveis referentes ao número de folhas e aos pesos das matérias secas, não apresentaram diferenças significativas entre os tratamentos.

Tabela 5. Médias das alturas e diâmetros; número de folhas; pesos das matérias secas da raiz de mudas de tomateiros com 27 dias de idade, submetidos aos tratamentos, no dia anterior ao do transplante no campo.

\begin{tabular}{lcccc}
\hline Tratamento & Altura (cm) & Diâmetro(mm) & $\mathbf{N}^{0}$.folhas & Peso S.Raiz(g) \\
\hline Testemunha & $16,11 \mathrm{a}$ & $2,70 \mathrm{c}$ & $6,00 \mathrm{a}$ & $0,084 \mathrm{a}$ \\
Agitação & $11,76 \mathrm{~b}$ & $2,99 \mathrm{~b}$ & $6,10 \mathrm{a}$ & $0,073 \mathrm{a}$ \\
Ventilação & $14,57 \mathrm{a}$ & $2,96 \mathrm{~b}$ & $6,20 \mathrm{a}$ & $0,085 \mathrm{a}$ \\
Esfregamento & $9,94 \mathrm{c}$ & $3,36 \mathrm{a}$ & $5,86 \mathrm{a}$ & $0,082 \mathrm{a}$ \\
\hline D.M.S. 5\% & 1,63 & 0,24 & 0,83 & 0,01 \\
CV (\%) & 7,74 & 4,99 & 8,53 & 13,28
\end{tabular}

Médias seguidas da mesma letra não diferem estatisticamente pelo teste de Tukey, ao nivel de $5 \%$ de probabilidade.

O condicionamento quando provoca um menor crescimento das mudas favorece um maior diâmetro delas, numa relação inversa; e ainda não interfere no desenvolvimento do sistema radicular, conforme podemos verificar na relação pesos das matérias secas da parte aérea/ da raiz. Já na relação aitura/diâmetro, o condicionamento reforça que há um menor desenvolvimento da altura, e um maior 
do diâmetro das mudas. Os resultados confirmam os obtidos por Latimer et al. (1991) em pepino, de que o condicionamento mecânico geralmente reduz menos o crescimento das raízes e reduz mais o crescimento da parte aérea.

O esfregamento mostrou-se ser o mais eficiente para o controle do crescimento das mudas, o mesmo comprovado em pepino, abóbora e melancia por Latimer \& Berverly (1994), e depois a agitação, também encontrada por Mitchell et al. (1975) e Heuchert \& Mitchell (1983) em tomateiros.

Tabela 6. Médias dos pesos das matérias secas: da parte aérea e total, relação peso da matéria seca da parteaérea/ peso da matéria seca da raiz, relação altu$\mathrm{ra} /$ diâmetro das mudas de tomateiros com 27 dias de idade submetidas aos tratamentos, no dia anterior ao do transplante no campo.

\begin{tabular}{|c|c|c|c|c|}
\hline Tratamento & $\begin{array}{l}\text { Peso Mat. Se. } \\
\text { Parte Aérea } \\
\text { (g) }\end{array}$ & $\begin{array}{l}\text { Peso Mat.Seca } \\
\text { total } \\
\text { (g) }\end{array}$ & $\begin{array}{l}\text { P.Mat.SecaPAé } \\
\text { rea/PesoMat.Se } \\
\text { ca Raiz }\end{array}$ & $\begin{array}{l}\text { Altura/Diâ } \\
\text { metro }\end{array}$ \\
\hline Testemunha & $0,233 \mathrm{a}$ & $0,318 \mathrm{a}$ & $2,819 \mathrm{ab}$ & $5,991 \mathrm{a}$ \\
\hline Agitação & $0,208 a$ & $0,282 a$ & $2,956 \mathrm{a}$ & $3,932 \mathrm{c}$ \\
\hline Ventilação & $0,220 \mathrm{a}$ & $0,305 a$ & $2,643 a b$ & $4,925 \mathrm{~b}$ \\
\hline Esfregamento & $0,201 \mathrm{a}$ & $0,283 \mathrm{a}$ & $2,505 \mathrm{~b}$ & $2,981 \mathrm{~d}$ \\
\hline D.M.S. $5 \%$ & 0,042 & 0,057 & 0,383 & 0,458 \\
\hline $\mathrm{CV}(\%)$ & 12,28 & 11,92 & 8,69 & 6,37 \\
\hline
\end{tabular}

Médias seguidas da mesma letra não diferem estatisticamente pelo teste de Tukey, ao nivel de $5 \%$ de probabilidade.

A Figura 4 ilustra os efeitos dos condicionamentos nas mudas de tomateiros com 27 dias de idade. 


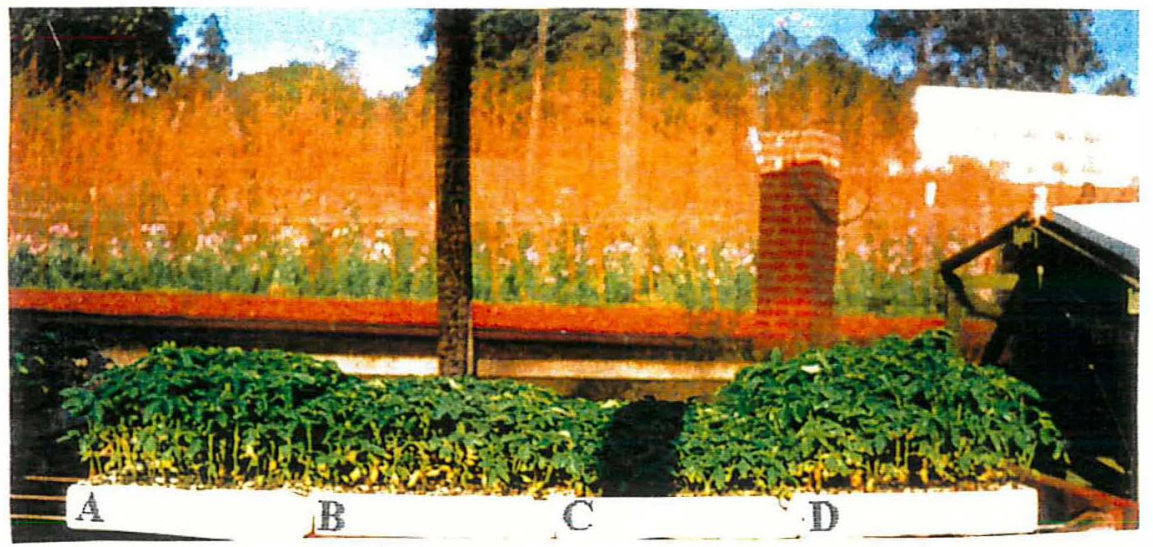

Figura 4. Aspectos dos efeitos da ventilação (A), agitação (B), esfregamento $(\mathrm{C})$, em relação a testemunha $(\mathrm{D})$.

\section{2. Pegamento das mudas}

Ảs avaliações foram efetuadas diariamente na primeira semana após o transplante, para todos os tratamentos inclusive a testemunha, não ocorrendo morte de plantas, sendo o pegamento de $100 \%$.

\section{3. Plantas}

\section{3. 1. Com dez dias de transplantadas}

A parte radicular das plantas devido a facilidade ainda para retirá-las do solo nessa época foi avaliada, e os resultados das médias obtidas encontram-se na Tabela 7. Ficou demonstrado que não ocorreram diferenças estatísticas signifi= cativas para as variáveis estudadas nessa época quanto ao peso da matéria seca da raiz, peso da matéria seca da parte aérea, peso da matéria seca total, e também da 
relação peso da matéria seca da parte aérea/peso da matéria seca da raiz, entretanto os tratamentos apresentaram valores numéricos maiores em relação a testemunha, evidenciando que as plantas passam a recuperá-los, desenvolvendo-se nomalmente.

As plantas condicionadas apresentaram aumento do peso da matéria seca também comprovado por Biddington \& Dearmann (1985a), Latimer (1990) em outras hortaliças, e aceleração do crescimento que também constataram Neel \& Harris (1972) em mudas de outras culturas, e Mitchell et al. (1975) em tomateiros, o que segundo estes autores pode caracterizar uma resistência aos estresses.

Tabela 7. Médias do pesos das matérias secas da raiz, da parte aérea e total, e da relação entre o peso da matéria seca da parte aérea/peso da matéria seca da raiz das plantas por tratamento, com dez dias após ao transplante no campo.

\begin{tabular}{lcccc}
\hline Tratamento & $\begin{array}{l}\text { Peso Matéria Peso Mat.Seca Peso Matéria PesoMat.Seca } \\
\text { Seca da Raiz }\end{array}$ & $\begin{array}{l}\text { da Parte Aérea } \\
\text { Seca total }\end{array}$ & $\begin{array}{c}\text { PAér/PesoMat } \\
\text { Seca da Raíz }\end{array}$ \\
\hline Testemunha & $0,167 \mathrm{a}$ & $0,699 \mathrm{a}$ & $0,867 \mathrm{a}$ & $4,339 \mathrm{a}$ \\
Agitação & $0,179 \mathrm{a}$ & $0,786 \mathrm{a}$ & $0,965 \mathrm{a}$ & $4,525 \mathrm{a}$ \\
Ventilação & $0,182 \mathrm{a}$ & $0,870 \mathrm{a}$ & $1,052 \mathrm{a}$ & $5,019 \mathrm{a}$ \\
Esfregamento & $0,171 \mathrm{a}$ & $0,819 \mathrm{a}$ & $0,990 \mathrm{a}$ & $5,053 \mathrm{a}$ \\
\hline D.M.S. 5\% & 0,028 & 0,275 & 0,286 & 1,670 \\
CV (\%) & 8,53 & 18,46 & 15,73 & 18,79
\end{tabular}

Médias seguidas da mesma letra não diferem estatisticamente pelo teste de Tukey, ao nivel de $5 \%$ de probabilidade. 


\section{3. 2 . Parte aérea aos dez, vinte e trinta dias após o transplante}

As Tabela 8 a 10 mostram as médias dos valores obtidos das plantas nas variáveis altura, diâmetro, número de folhas e peso da matéria seca da parte aérea, observados aos dez, vinte e trinta dias após o transplante das mudas. Apenas ocorreram diferenças significativas para as variáveis altura e altura/diâmetro com dez dias e altura/diâmetro com trinta dias após o transplante, essas médias quando comparadas com as médias das mudas com 27 dias de idade, verifica-se que os tratamentos condicionadores apresentaram maior desenvolvimento em relação as testemunhas. Isso demonstra que os tratamentos apenas alteram essas variáveis enquanto estão sendo aplicados, concordando com Latimer (1991), pois após o seu término as plantas voltam a desenvolver-se normalmente e não apresentam diferenças significativas entre si.

Tabela 8. Médias das alturas em centímetros, dos diâmetros em milímetros, nú mero de folhas, peso da matéria seca da parte aérea em $\mathrm{g}$, relação altu ra/diâmetro das mudas por tratamento com dez dias após o transplante no campo.

\begin{tabular}{lccccc}
\hline Tratamento & Altura & Diâmetro & $\mathbf{N}^{\circ}$.Folhas & $\begin{array}{c}\text { P.Mat.Seca } \\
\text { Part.Aérea }\end{array}$ & Altu/Dlâm \\
\hline Testemunha & $18,65 \mathrm{a}$ & $3,76 \mathrm{a}$ & $8,42 \mathrm{a}$ & $0,699 \mathrm{a}$ & $5,04 \mathrm{a}$ \\
Agitação & $16,29 \mathrm{~b}$ & $3,98 \mathrm{a}$ & $8,96 \mathrm{a}$ & $0,786 \mathrm{a}$ & $4,12 \mathrm{~b}$ \\
Ventilação & $18,16 \mathrm{a}$ & $4,04 \mathrm{a}$ & $9,12 \mathrm{a}$ & $0,870 \mathrm{a}$ & $4,51 \mathrm{~b}$ \\
Esfregamento & $14,41 \mathrm{c}$ & $4,00 \mathrm{a}$ & $8,98 \mathrm{a}$ & $0,819 \mathrm{a}$ & $3,63 \mathrm{c}$ \\
\hline D.M.S. 5\% & 1,51 & 0,43 & 1,19 & 0,268 & 0,420 \\
CV (\%) & 4,93 & 6,14 & 7,46 & 18,70 & 5,35
\end{tabular}

Médias seguidas da mesma letra não diferem estatisticamente pelo teste de Tukey, a $5 \%$. 
Tabeia 9. Médias das aituras em centimetros, dos diâmetros em milimetros, nú mero le folhas, peso da matéria seca da parte aérea em g, relação altu ra/diâmetro das mudas por tratamento com vinte dias após o transplante no campo.

\begin{tabular}{lccccc}
\hline Tratamento & Altura & Diâmetro & $\mathbf{N}^{\circ}$.Folhas & $\begin{array}{c}\text { P.Mat.Seca } \\
\text { Part. Aérea }\end{array}$ & Altu/Diâm \\
\hline Testemunha & $27,84 \mathrm{a}$ & $5,28 \mathrm{a}$ & $14,63 \mathrm{a}$ & $2,460 \mathrm{a}$ & $5,41 \mathrm{a}$ \\
Agitação & $26,04 \mathrm{a}$ & $5,30 \mathrm{a}$ & $14,64 \mathrm{a}$ & $2,597 \mathrm{a}$ & $4,96 \mathrm{a}$ \\
Ventilação & $30,10 \mathrm{a}$ & $5,98 \mathrm{a}$ & $18,82 \mathrm{a}$ & $3,494 \mathrm{a}$ & $5,09 \mathrm{a}$ \\
Esfregamento & $25,00 \mathrm{a}$ & $5,45 \mathrm{a}$ & $15,40 \mathrm{a}$ & $2,846 \mathrm{a}$ & $4,64 \mathrm{a}$ \\
\hline D.M.S. 5\% & 5,17 & 1,06 & 4,80 & 1,49 & 0,78 \\
CV (\%) & 10,48 & 10,63 & 16,72 & 28,99 & 8,65 \\
\hline
\end{tabular}

Médias seguidas da mesma letra não diferem estatisticamente pelo teste de Tukey.

Tabela 10. Médias das alturas em centímetros, dos diâmetros em milimetros, número de folhas, peso da matéria seca da parte aérea em g, relação altura/diâmetro das mudas por tratamento com trinta dias após o transplante no campo.

\begin{tabular}{lccccc}
\hline Tratamento & Altura & Diâmetro & $\mathbf{N}^{0}$.Folhas & $\begin{array}{c}\text { P.Mat.Seca } \\
\text { Part. Aérea }\end{array}$ & Altu/Dlâm \\
& & & & & \\
\hline Testemunha & $42,51 \mathrm{a}$ & $7,51 \mathrm{a}$ & $23,57 \mathrm{a}$ & $7,987 \mathrm{a}$ & $5,74 \mathrm{a}$ \\
Agitação & $43,98 \mathrm{a}$ & $8,17 \mathrm{a}$ & $31,30 \mathrm{a}$ & $10,292 \mathrm{a}$ & $5,47 \mathrm{~b}$ \\
Ventilação & $46,09 \mathrm{a}$ & $8,94 \mathrm{a}$ & $32,72 \mathrm{a}$ & $11,430 \mathrm{a}$ & $5,23 \mathrm{~b}$ \\
Esfregamento & $45,36 \mathrm{a}$ & $9,06 \mathrm{a}$ & $30,77 \mathrm{a}$ & $11,433 \mathrm{a}$ & $5,06 \mathrm{~b}$ \\
\hline D.M.S. 5\% & 10,44 & 2,30 & 18,75 & 7,45 & 0,47 \\
CV (\%) & 12,96 & 15,09 & 34,99 & 40,03 & 4,91 \\
\hline
\end{tabular}

Médias seguidas da mesma letra não diferem estatisticamente pelo teste de Tukey, a $5 \%$. 
As médias das variáveis estudadas nos tratamentos apresentaram valores numéricos maiores para o tratamento ventilação já após vinte dias do transplante, com exceção da variável relação altura/diâmetro, embora estas diferenças não fossem significativas. Nota-se ainda que o peso da matéria seca da parte aérea recuperou-se em relação a testemunha, confumando o encontrado por Liptay (1985), em mudas de tomateiro submetidas a vibrações por corrente de ar após três semanas no campo.

A Tabela 11 apresenta as médias das variáveis estudas das três idades observadas no campo. Apenas para a variável da relação altura das plantas/ diâmetro das plantas referentes aos três tempos observados é que os tratamentos apresentaram diferenças significativas. A testemunha e esfregamento diferiram entre si e dos demais quanto a esta variável, ficando este último condicionamento com valores abaixo dos demais, o que mantém a coerêtrcia quanto aos observados para a mesma variável nas mudas; demonstra também que com o decorrer do tempo as plantas começam a diminuir essas diferenças. Nas demais variáveis as diferenças numéricas não foram significativas.

Tabela 11.Médias de plantas avaliadas aos 10,20 e 30 dias tempo dos tratamentos

\begin{tabular}{lccccc}
\hline Tratamento & Altura & Dlâmetro & $\mathbf{N}^{\circ}$.Folhas & PSAérea & Altu/Diâm \\
\hline Testemunha & $29,674 \mathrm{a}$ & $5,521 \mathrm{a}$ & $15,54 \mathrm{a}$ & $3,716 \mathrm{a}$ & $5,402 \mathrm{a}$ \\
Agitação & $28,773 \mathrm{a}$ & $5,821 \mathrm{a}$ & $18,30 \mathrm{a}$ & $4,558 \mathrm{a}$ & $4,855 \mathrm{~b}$ \\
Ventilação & $31,455 \mathrm{a}$ & $6,324 \mathrm{a}$ & $20,22 \mathrm{a}$ & $5,265 \mathrm{a}$ & $4,947 \mathrm{~b}$ \\
Esfregamento & $28,262 \mathrm{a}$ & $6,173 \mathrm{a}$ & $18,38 \mathrm{a}$ & $5,033 \mathrm{a}$ & $4,448 \mathrm{c}$ \\
\hline D.M.S. 5\% & 3,752 & 0,815 & 6,19 & 2,412 & 0,315 \\
CV $(\%)$ & 13,02 & 14,02 & 35,02 & 53,24 & 6,59
\end{tabular}

Médias seguidas da mesma letra não diferem estatisticamente pelo teste de Tukey, ao nivel de $5 \%$ de probabilidade. 
As plantas provenientes de mudas condicionadas parecem acelerar o seu desenvolvimento no campo, diminuindo as diferenças em relação a testemunha, desenvolvendo-se mais que esta, embora estatísticamente estas diferenças não foram significativas.

A Tabela 12 mostra a correlação linear das variáveis estudadas e do tempo, destacando as equações polinomiais para cada tratamento na variável altura/diâmetro, pois as demais variáveis não apresentaram diferenças significativas.

Tabela 12. Equações Polinomiais referentes as variáveis estudadas

\begin{tabular}{lll}
\hline Variável & Equacão & $\underline{\mathbf{R}^{2}}$ \\
\hline Altura & $\mathrm{y}=1.935001+1.3803250^{*}$ Tempo & $0,98^{* *}$ \\
Diâmetro & $\mathrm{y}=1.484917+0.2237625^{*}$ Tempo & $0,97^{* *}$ \\
Número de Folhas & $\mathrm{y}=-2.611666+1.0362500 *$ Tempo & $0,96^{* *}$ \\
Peso mat.seca P. Aérea & $\mathrm{y}=-4.848636+0.4745950^{*}$ Tempo & $0,90^{* *}$ \\
Altura/Diâmetro & $\mathrm{y}=3.862628+0.0525395 *$ Tempo & $0,96^{* *}$ \\
\hline
\end{tabular}

Equação polinomial da variável Altura/Diâmetro para cada tratamento

\begin{tabular}{lll} 
Tratamento & Equacão & $\underline{\mathbf{R}^{2}}$ \\
\hline Testemunha & $\mathrm{y}=4.704140+0.0349180^{*}$ Tempo & $0,99^{* *}$ \\
Agitação & $\mathrm{y}=3.501787+0.0676930 *$ Tempo & $0,98^{* *}$ \\
Ventilação & $\mathrm{y}=4.226434+0.0360480 *$ Tempo & $0,88^{* *}$ \\
Esfregamento & $\mathrm{y}=3.018153+0.0714990 *$ Tempo & $0,94^{* *}$
\end{tabular}

**Significativo ao nível mínimo de significância de $1 \%$.

\section{3. 3 Avaliação do Florescimento}

Foram levantadas as plantas em relação a ántese das flores, sendo a contagem realizadas nos dias $03,07,10$ e 13 de setembro ou seja aos 19, 23, 26 e 29 dias após o transplante das mudas, a média do número das plantas com flores 
abertas, valores são acumulados a partir da primeira contagem, e a média do número de plantas nas parcelas para cada contagem, encontram-se na Tabela 13. Verificamos que parece ocorrer uma maior tendência de florescimento antecipado de plantas para os tratamentos condicionadores; por ordem decrescente do número de plantas com flores abertas os tratamentos esfregamento e ventilação, iguais na última avaliação em valores numéricos, foram seguidos dos tratamentos agitação e testemunha, respectivamente com menor número de plantas com flores abertas. Por ser os valores das plantas com flores abertas acumulativos não foi efetuada a análise estatística.

Tabela 13. Médias do número de plantas com flores acumuladas (CF) por trata mento, e médias do número de plantas nas parcelas (NP)

\begin{tabular}{ccccccccc}
\hline Dlas após o & \multicolumn{2}{c}{ Testemunha } & \multicolumn{2}{c}{ Agitação } & \multicolumn{2}{c}{ Ventilação } & \multicolumn{2}{c}{ Esfregamento } \\
transplante & CF & NP & CF & NP & CF & NP & CF & NP \\
\hline 19 dias & 1,6 & 120 & 2 & 120 & 3 & 120 & 5,6 & 120 \\
23 dias & 8,8 & 102,2 & 15,6 & 104,0 & 13,4 & 104,2 & 20 & 104,4 \\
26 dias & 23,8 & 85,8 & 28,2 & 83,9 & 36 & 91,0 & 38,8 & 86,4 \\
29 dias & 51 & 85,8 & 60,2 & 83,9 & 67,8 & 91,0 & 67,8 & 86,4 \\
\hline
\end{tabular}

A Figura 5 relaciona o número de plantas com flor aberta e desta quantas apresentavam mais de uma flor aberta, aos 29 dias da cultura no campo. As plantas dos condicionamentos apresentaram maior número de plantas com flores abertas. 
PLANTAB COM FLORES E COM MAS DE UMA FLOR

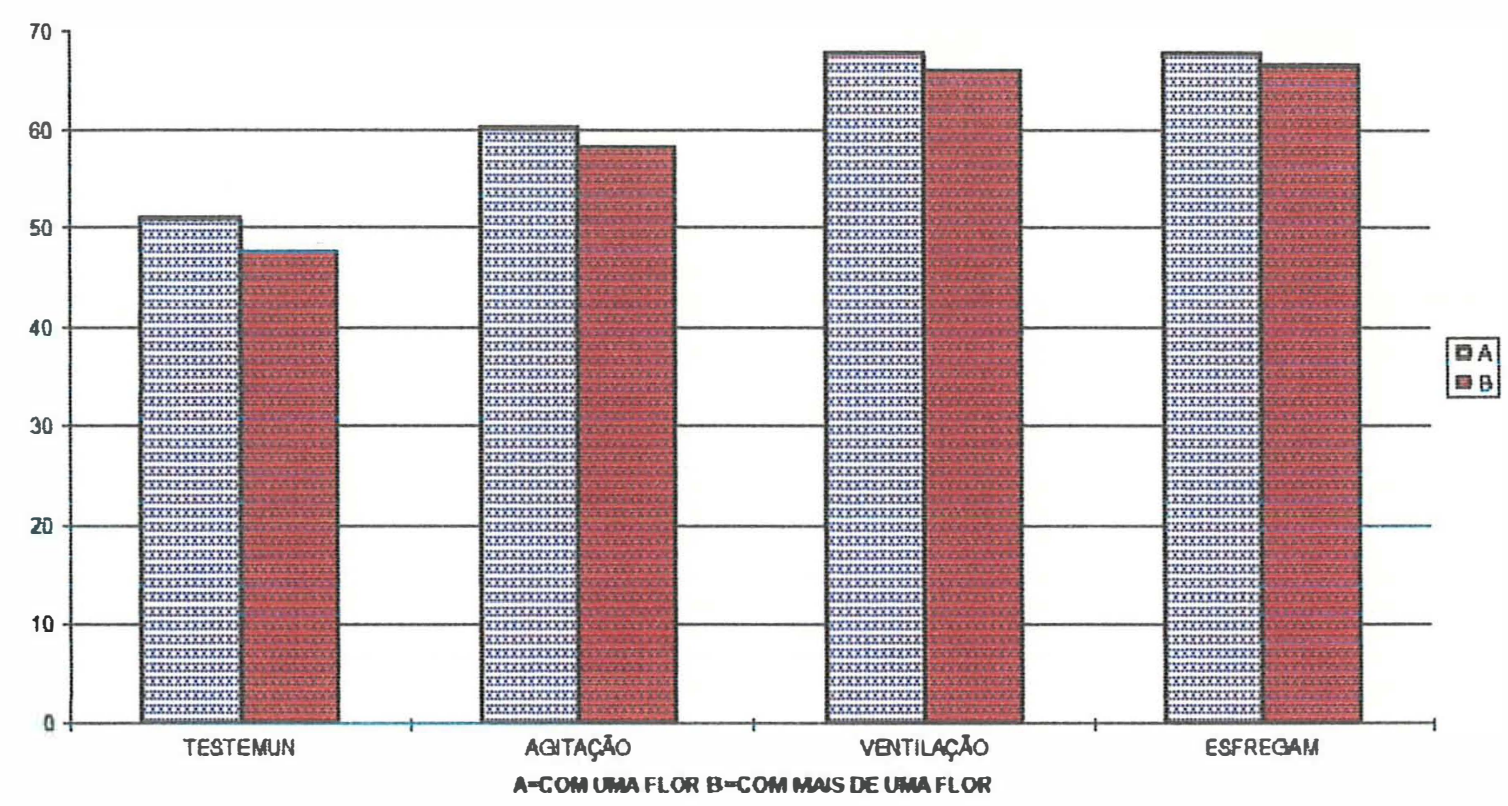

Figura 5. Número de plantas com flores acumuladas aos 29 dias após o transplante.

\section{3. 4 Colheita}

A colheita teve início no dia 19/10/95 e foi efetuada pelo menos uma vez por semana, sempre no mesmo dia em todas as parcelas, estendendo-se até o dia 21/11/95; o período de produção foi prejudicado tendo em vista que na manhã do dia 20/10/95, forte chuva de granizo e ventos atingiu o município e a área experimental do Departamento, o que provavelmente sejam responsáveis pela baixa produção nas parcelas, diminuindo o período de colheita.

As análises revelaram que não houve diferenças significativas entre os tratamentos quanto ao peso e número de frutos tanto comerciais como não comerciais, e tampouco quanto a produção total, dados que comprovam os constatados por Pardossi et al. (1988) em tomateiros escovados e transplantados em estufa, 
e por Johjima et al. (1992) para o condicionamento escovamento em sete cultivares de tomateiros estudados. Todavia, ocorreram diferenças significativas de produção entre as semanas, porém não entre os tratamentos. Os resultados encontram-se nas Tabelas 14 a 15 .

Tabela 14. Médias de tratamentos das variáveis peso de frutos comerciais, número de frutos comerciais e peso médio do fruto comercial, obtidos na colheita das parcelas de tamanho $3,2 \mathrm{~m} \times 4,0 \mathrm{~m}$, tendo como co-variável o número de plantas.

\begin{tabular}{|c|c|c|c|}
\hline Tratamento & $\begin{array}{l}\text { Peso dos Frutos } \\
\text { Comerciais (kg) }\end{array}$ & $\begin{array}{l}\text { Número de Frutos } \\
\text { Comerciais }\end{array}$ & $\begin{array}{l}\text { PesoMédioFruto } \\
\text { Comercial (g) }\end{array}$ \\
\hline Testemunha & $6,307 \mathrm{a}$ & $65,60 a$ & $94,67 \mathrm{a}$ \\
\hline Agitação & $6,011 \mathrm{a}$ & $65,00 a$ & $92,60 \mathrm{a}$ \\
\hline Ventilação & $8,013 \mathrm{a}$ & $84,20 a$ & $95,20 \mathrm{a}$ \\
\hline Esfregamento & 6,993 a & $74,40 \mathrm{a}$ & $93,85 \mathrm{a}$ \\
\hline D.M.S. 5\% & 4,010 & 37,466 & 11,824 \\
\hline CV (\%) & 31,25 & 27,59 & 6,69 \\
\hline
\end{tabular}

Médias seguidas da mesma letra não diferem estatisticamente pelo teste de Tukey, ao nivel de $5 \%$ de probabilidade.

Pelas médias observa-se uma tendência do tratamento ventilação proporcionar maior produção e maior número de frutos tanto comercial como não comercial e ainda maior peso individual do fruto comercial, embora estas diferenças não tenharn sido significativas estatisticamente. 
Tabela 15. Médias de tratamentos das variáveis pesos de frutos não comerciais, número de não comerciais, média do número de plantas doentes, obti dos na colheita das parcelas, tendo como co-variável o número de plan tas na parcela, peso em quilograma.

\begin{tabular}{lccc}
\hline Tratamento & $\begin{array}{c}\text { Peso dos } \\
\text { Não Comerciais }\end{array}$ & $\begin{array}{c}\text { Futos } \\
\text { Não Comerciais }\end{array}$ & $\begin{array}{c}\text { Número de Plan- } \\
\text { tas Doentes }\end{array}$ \\
\hline Testemunha & $13,101 \mathrm{a}$ & $276,00 \mathrm{a}$ & $6,80 \mathrm{a}$ \\
Agitação & $10,593 \mathrm{a}$ & $234,40 \mathrm{a}$ & $7,20 \mathrm{a}$ \\
Ventilação & $14,042 \mathrm{a}$ & $290,80 \mathrm{a}$ & $6,20 \mathrm{a}$ \\
Esfregamento & $13,421 \mathrm{a}$ & $286,40 \mathrm{a}$ & $6,40 \mathrm{a}$ \\
\hline D.M.S. 5\% & 6,951 & 121,57 & 6,04 \\
CV (\%) & 28,94 & 23,81 & 48,40 \\
\hline Médias seguidas da mesma letra não diferem estatisticamente pelo teste de Tukey, \\
ao nivel de 5\% de probabilidade.
\end{tabular}

Tabela 16. Médias de produção obtida, em quilos, por colheita e por tratamento.

\begin{tabular}{lcccc}
\hline Semana & Testemunha & Agitação & Ventilação & Esfregamento \\
\hline Primeira & $1,833 \mathrm{~b}$ & $2,380 \mathrm{ab}$ & $2,323 \mathrm{bc}$ & $2,332 \mathrm{~b}$ \\
Segunda & $1,516 \mathrm{~b}$ & $1,599 \mathrm{~b}$ & $1,921 \mathrm{bc}$ & $2,325 \mathrm{~b}$ \\
Terceira & $6,027 \mathrm{a}$ & $4,631 \mathrm{a}$ & $7,044 \mathrm{a}$ & $7,148 \mathrm{a}$ \\
Quarta & $3,577 \mathrm{ab}$ & $3,180 \mathrm{ab}$ & $4,385 \mathrm{~b}$ & $3,307 \mathrm{~b}$ \\
Quinta & $2,995 \mathrm{~b}$ & $2,542 \mathrm{ab}$ & $3,206 \mathrm{bc}$ & $2,631 \mathrm{~b}$ \\
Sexta & $1,476 \mathrm{~b}$ & $1,235 \mathrm{~b}$ & $1,426 \mathrm{c}$ & $0,942 \mathrm{~b}$ \\
Sétima & $1,984 \mathrm{~b}$ & $1,046 \mathrm{~b}$ & $1,750 \mathrm{c}$ & $1,621 \mathrm{~b}$ \\
\hline
\end{tabular}

Médias seguidas de letras iguais não diferem estatísticamente ao nivel de $5 \%$, CV $(\%)=46,50$, D.M.S $5 \%=2,464$ 
Dentro de cada tratamento ocorreram diferenças significativas entre as colheitas como se verifica pela Tabela 16, na qual a terceira colheita foi a mais produtiva em todos os tratamentos quando analisados separadamente. As análises de cada colheita comparadas entre os tratamentos mostraram apenas diferenças significativas para a terceira colheita conforme a Tabela 17, onde o tratamento agitação diferenciou-se dos demais sendo o menor em produção para esta colheita, enquanto que os tratamentos esfregamento, ventilação sendo os mais produtivos não diferenciaram da testemunha estatisticamente ao nivel de $5 \%$ de significancia.

Tabela 17. Médias de produção obtida, em quilos, por colheita, total de produção por tratamento.

\begin{tabular}{lcccc}
\hline Semana & Testemunha & Agitação & Ventilação & Esfregamento \\
\hline Primeira & $1,833 \mathrm{a}$ & $2,380 \mathrm{a}$ & $2,323 \mathrm{a}$ & $2,332 \mathrm{a}$ \\
Segunda & $1,516 \mathrm{a}$ & $1,599 \mathrm{a}$ & $1,921 \mathrm{a}$ & $2,325 \mathrm{a}$ \\
Terceira & $6,027 \mathrm{ab}$ & $4,631 \mathrm{~b}$ & $7,044 \mathrm{a}$ & $7,148 \mathrm{a}$ \\
Quarta & $3,577 \mathrm{a}$ & $3,180 \mathrm{a}$ & $4,385 \mathrm{a}$ & $3,307 \mathrm{a}$ \\
Quinta & $2,995 \mathrm{a}$ & $2,542 \mathrm{a}$ & $3,206 \mathrm{a}$ & $2,631 \mathrm{a}$ \\
Sexta & $1,476 \mathrm{a}$ & $1,235 \mathrm{a}$ & $1,426 \mathrm{a}$ & $0,942 \mathrm{a}$ \\
Sétima & $1,984 \mathrm{a}$ & $1,046 \mathrm{a}$ & $1,750 \mathrm{a}$ & $1,621 \mathrm{a}$ \\
\hline
\end{tabular}

Letras iguais não diferem entre si estatísticamente ao nível de $5 \%$ pelo teste de Tukey, CV $(\%)=46,50$, D.M.S. $5 \%=2,144$

A produção média total dos tratamentos também não apresentou diferenças significativas, tendo em valores numéricos os tratamentos esfregamento e ventilação apresentados maiores médias, conforme verifica-se na Tabela 18. 
TABELA 18. Médias das produções totais das parcelas de tamanha 4,0m X 3,2m $\left(12,8 \mathrm{~m}^{2}\right)$ dos tratamentos.

\begin{tabular}{lcccc}
\hline Produção & Testemunha & Agitação & Ventllação & Esfregamento \\
\hline TOTAL & $19,408 \mathrm{a}$ & $16,613 \mathrm{a}$ & $22,055 \mathrm{a}$ & $20,306 \mathrm{a}$ \\
\hline
\end{tabular}

Letras iguais não diferem entre si estatísticamente ao nível de $5 \%$ pelo teste de Tukey, CV(\%) 30,44 , D.M.S. $5 \%=10.804$.

A Figura 6 mostra e compara os resultados de cada colheita entre os tratamentos, verificamos que apenas para a terceira colheita houve diferenças para a agitação em relação a ventilação e ao esfregamento.

PRODUÇÃO MÉDIA TOTAL POR COLHEITAE POR TRATAMENTO

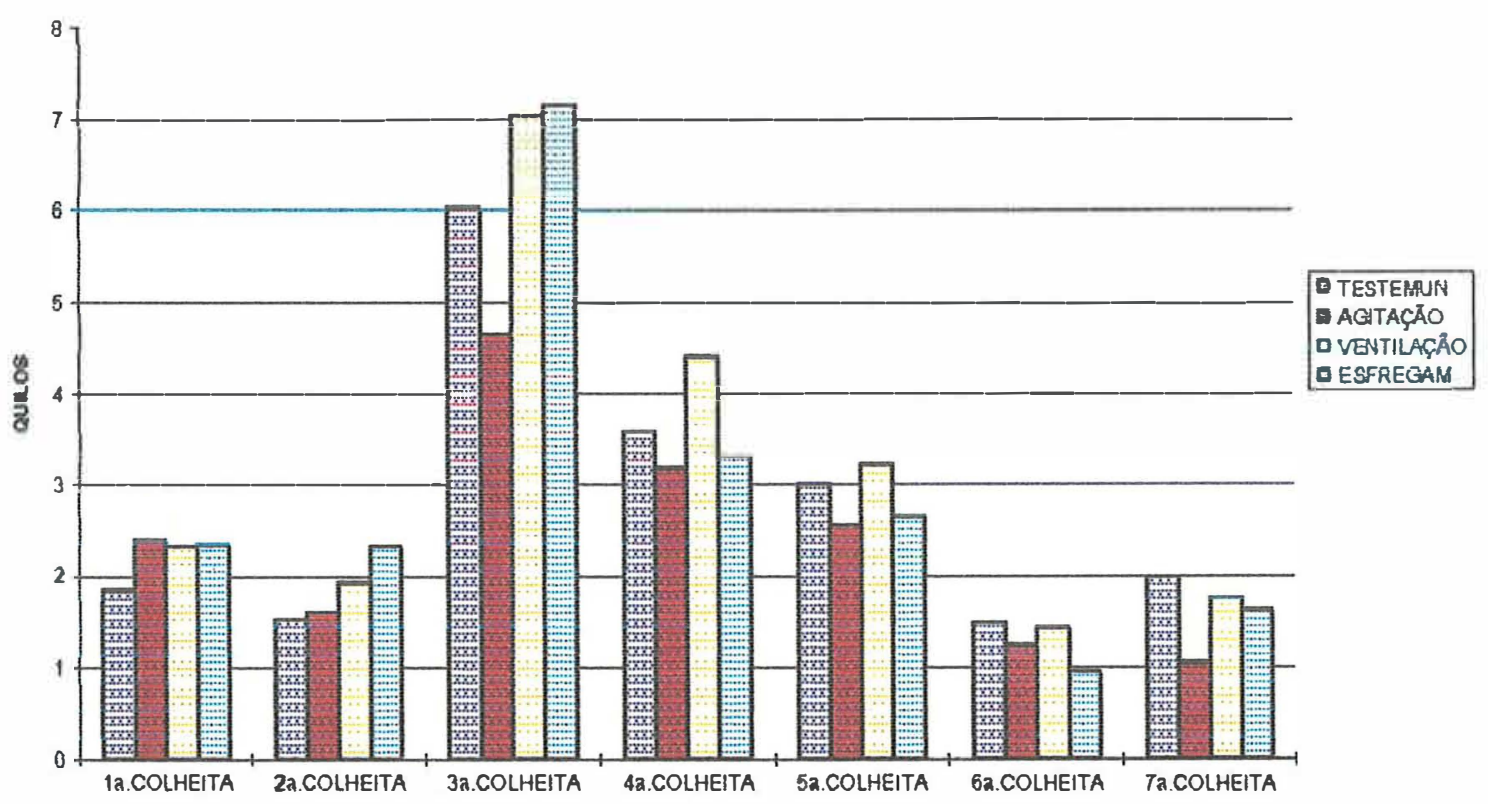

Figura 6. Média das produções em quilos por colheita e por tratamento 
As Tabelas 19 e 20 referem-se ao número de plantas colhidas.

Tabela 19. Médias do número de plantas colhidas por vez (colheita) no tratamento

\begin{tabular}{lcccc}
\hline Colheita & Testemunha & Agitação & Ventilação & Esfregamento \\
\hline Primeira & $7,8 \mathrm{c}$ & $11,2 \mathrm{ab}$ & $10,0 \mathrm{c}$ & $9,8 \mathrm{~b}$ \\
Segunda & $10,8 \mathrm{bc}$ & $11,0 \mathrm{ab}$ & $11,0 \mathrm{bc}$ & $14,6 \mathrm{ab}$ \\
Terceira & $21,4 \mathrm{a}$ & $18,6 \mathrm{a}$ & $22,4 \mathrm{a}$ & $22,0 \mathrm{a}$ \\
Quarta & $18,0 \mathrm{ab}$ & $16,6 \mathrm{ab}$ & $20,2 \mathrm{ab}$ & $16,6 \mathrm{ab}$ \\
Quinta & $13,8 \mathrm{abc}$ & $14,8 \mathrm{ab}$ & $15,0 \mathrm{abc}$ & $12,6 \mathrm{ab}$ \\
Sexta & $11,4 \mathrm{bc}$ & $8,4 \mathrm{~b}$ & $10,8 \mathrm{bc}$ & $7,6 \mathrm{~b}$ \\
Sétima & $14,2 \mathrm{abc}$ & $12,4 \mathrm{ab}$ & $12,6 \mathrm{bc}$ & $13,0 \mathrm{ab}$ \\
\hline Letras distintas diferem entre si ao nível de $5 \%, \mathrm{CV}(\%)=36,57$, D.M.S. $5 \%=9,6$.
\end{tabular}

Tabela 20. Médias do número de plantas colhidas por vez (colheita) por tratamento e resultado do teste de Tukey a $5 \%$ das colheitas individuais entre os tratamentos.

\begin{tabular}{lcccc}
\hline Colheita & Testemunha & Agitação & Ventilação & Esfregamento \\
\hline Primeira & $7,8 \mathrm{a}$ & $11,2 \mathrm{a}$ & $10,0 \mathrm{a}$ & $9,8 \mathrm{a}$ \\
Segunda & $10,8 \mathrm{a}$ & $11,0 \mathrm{a}$ & $11,0 \mathrm{a}$ & $14,6 \mathrm{a}$ \\
Terceira & $21,4 \mathrm{a}$ & $18,6 \mathrm{a}$ & $22,4 \mathrm{a}$ & $22,0 \mathrm{a}$ \\
Quarta & $18,0 \mathrm{a}$ & $16,6 \mathrm{a}$ & $20,2 \mathrm{a}$ & $16,6 \mathrm{a}$ \\
Quinta & $13,8 \mathrm{a}$ & $14,8 \mathrm{a}$ & $15,0 \mathrm{a}$ & $12,6 \mathrm{a}$ \\
Sexta & $11,4 \mathrm{a}$ & $8,4 \mathrm{a}$ & $10,8 \mathrm{a}$ & $7,6 \mathrm{a}$ \\
Sétima & $14,2 \mathrm{a}$ & $12,4 \mathrm{a}$ & $12,6 \mathrm{a}$ & $13,0 \mathrm{a}$ \\
\hline
\end{tabular}

Médias seguidas da mesma letra não diferem entre si ao nível de $5 \%$, Teste Tukey. CV $(\%)=36,57$, D.M.S. $5 \%=3,16$. 


\section{3. 5. Altura final das plantas e comprimento do segundo internódio}

Ainda no final do ciclo da cultura foram estudados a altura final (medida entre o colo da planta e a gema apical), e o comprimento do segundo internódio (a distancia entre os dois nós iniciais) das plantas nas parcelas, entre os tratamentos, não tendo sido encontrada diferença significativa entre os mesmos. Em valores numéricos as plantas do tratamento testemunha foram as que menos desenvolveram em altura, sendo o tratamento ventilação aquele que apresentou maior desenvolvimento em média na altura e no comprimento do segundo internódio das plantas, embora estas diferenças não tenham sido significativas.

A Tabela 21 apresenta as diferenças numéricas ocorridas entre as médias dos tratamentos e a testemunha para as variáveis altura final das plantas e comprimento do segundo internódio.

Tabela 21. Médias de tratamentos das variáveis altura final de plantas e comprimento do segundo internódio èm centímetros, após a última colheita.

\begin{tabular}{lcc}
\hline \multicolumn{1}{c}{ Tratamento } & Altura final & Compr. do seg.Internódio \\
\hline Testemunha & $121,92 \mathrm{a}$ & $4,94 \mathrm{a}$ \\
Agitação & $125,62 \mathrm{a}$ & $4,63 \mathrm{a}$ \\
Ventilação & $131,86 \mathrm{a}$ & $5,05 \mathrm{a}$ \\
Esfregamento & $130,35 \mathrm{a}$ & $4,20 \mathrm{a}$ \\
\hline D.M.S. 5\% & 22,736 & 1,82 \\
CV (\%) & 9,50 & 20,69 \\
\hline Médias seguidas da mesma letra não diferem estatisticamente pelo teste de Tukey, \\
ao nivel de 5\% de probabilidade.
\end{tabular}




\section{CONCLUSÕES}

Para as condições do experimento, concluiu-se que:

1. Os tratamentos condicionadores apresentaram efeitos nas plantas durante o periodo em que foram aplicados, na parte aérea, não afetando o sistema radicular. Com relação a altura das mudas aos 27 dias de idade, os tratamentos agitação e esfregamento diferiram estatísticamente da testemunha, enquanto que ventilação não mostrou essa diferença. Com relação ao diâmetro todos os tratamentos diferiram estatísticamente da testemunha, sendo que a agitação e ventilação não apresentaram diferenças significativas entre si.

2. O esfregamento, com maior intensidade, e a agitação proporcionaram mudas de 27 dias de idade com altura inferior aos demais tratamentos.

3. O esfregamento proprocionou mudas de 27 dias de idade com diâmetro superior aos demais tratamentos.

4. Aos 20 e 30 đias após o transplante para o campo, as diferenças de altura e diâmetro das plantas entre os tratamentos não mais se verificaram.

5. Os tratamentos condicionadores estimularam o desenvolvimento das plantas no campo. A ventilação apresentou uma tendência a maior produção

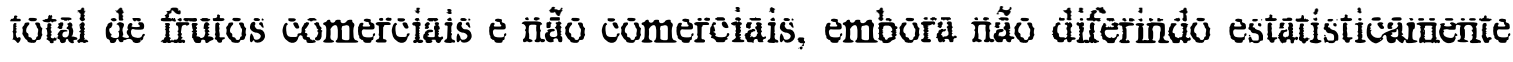
dos demais tratamentos. 
6. Os tratamentos condicionadores não apresentaram efeitos negativos em nenhuma fase do ciclo da cultura. Os tratamentos pareceram antecipar o florescimento nas plantas, bem como proporcionaram maior número de flores aos 29 dias após o transplante.

7. O uso moderado de ventiladores direto nas mudas em estufas, não trouxe nenhum efeito negativo ao desenvolvimento posterior delas no campo.

8. Necessário se toma repetir tais tratamentos, em outras regiões e épocas diferentes com condicões climáticas diferentes, até com outros cultivares, para concluir se as diferenças numéricas se confinmam para o tratamento ventilação, e atribuir ao mesmo a causa dessas diferenças. 


\section{REFERÊNCIAS BIBLIOGRÁFICAS}

ADLER, P. R.; WILCOX, G. E. Salt stress, mechanical stress, or chlormequat chloride effects on morphology and growth recovery of hydroponic tomato transplants. Journal of the American Society for Horticultural Science, v. 112 , n. 1, p. 22-5, Jan. 1987.

AKERS, S. W.; MTCHELL, C. A. Seismic stress effects on vegetative and reproductive development of 'alaska' Pea. Canadian Journal of Botany, v. 62, n. 10, p. $2011-5$, Oct. 1984.

AKERS, S.W.; MITCHELL, C.A. Seismic stress effects on reproductive structures of tomato, potato, and marigold. HortScience, v. 20, n. 4, p. 684-6, Aug. 1985 .

BEYL, C. A; MITCHELL, C. A Automated mechanical stress application for height control of greenhouse chrysanthemum. HortScience, v. 12,n. 6,p. 575-7, Dec. 1977a.

BEYL, C. A; MITCHELL, C. A Characterization of mechanical stress dwarfing in chrysanthemum. Journal of the American Society for Horticultural Science, v. 102, n. 5, p. 591-4, Sept. 1977 b.

BEYL, C. A; MITCHELL, C. A. Alteration of growth, exudation rate, and endogenous hormone profiles in mechanically dwarfed sunflower. Journal of the American Society for Horticultural Science, v. 108, n. 2, p. 257-62, Mar. 1983. 
BIDDINGTON, N. L.; DEARMAN, A. S. The effect of mechanically induced stress on the growth of cauliflower, lettuce and celery seedlings. Annals of Botany, v. 55, n. 1, p. 109-19, Jan. 1985a.

BIDDINGTON, N. L.; DEARMAN, A S. The effects of mechanically-induced stress on water loss and drought resistance in lettuce, cauliflower and celery seedlings. Annals of Botany, v. 56, n. 6, p. 795-802, Dec. 1985b.

BIDDINGTON, N. L.; DEARMAN, A. S. A comparison of the effects of mechanically-induced stress, ethephon and silver thiosulphate on the growth of cauliflower seedlings. Plant Growth Regulation, v. 4, p. 33-41, Mar. 1986.

BIDDINGTON, N. L.; DEARMAN, A. S. The effects of mechanically-induced stress on the growth of water and nutrient deficient lettuce and cauliflower seedlings. Annals of Botany, v. 59, n. 6, p. 679-83, June 1987.

BIDDINGTON, N. L.; DEARMAN, A. S. The effects of mechanically-induced stress and water stress on freezing resistance in lettuce and cauliflower seedlings. Journal of Horticultural Science, v. 63, n. 4, p. 609-14, Oct. 1988.

CAMARGO FILHO, W.P.; MAZZEI, A.R.Necessidade de Reconversão da Produção de Tomate em São Paulo: Ações na Cadeia Produtiva. Informações Econômicas, v.26, n. 6, p. 105 - 11, Jun. 1996.

HEUCHERT, J. C.; MITCHELL, C. A Inhibition of shoot growth in greenhousegrown tomato by periodic gyratory shaking. Journal of the American Society for Horticultural Science, v. 108, n. 5, p. 795-800, Sept. 1983. 
HEUCHERT, J. C.; MARKS, J. S.; MITCHELL, C. A Strengthening of tomato shoots by gyratory shaking. Journal of the American Society for Hortlcultural Science, v. 108, n. 5, p. 801-5, Sept. 1983.

HAMMER, P. A; MITCHELL, C. A; WEILER, T. C. Height control in greenhouse chrysanthemum by mechanical stress. HortScience, v. 9, n. 5,p. 474- 5, Oct. 1974.

JOHIMA, T.; LATIMER, J. G.; WAKITA, H. Brushing influences transplant growth and subsequent yield of four cultivars of tomato and their hybrid lines. Journal of the American Society for Horticultural Science, v. 117, n. 3, p. 384-8, May 1992.

LATIMER, J. G. Drought or mechanical stress affects broccoli transplant growth and establishment but not yield. HortScience, v. 25, n.10, p.1233-5, Oct.1990.

LATIMER, J. G. Feature, mechanical conditioning for control of growth and quality of vegetable transplants. HortScience, v. 26, n.12, p.1456-61, Dec. 1991.

LATIMER, J. G.; BEVERLY, R. B. Conditioning affects growth and drought tolerance of cucurbit transplants. Journal of the American Society for Horticultural Science, v. 119, n.5, p.943-8, Sept. 1994.

LATIMER, J. G.; MITCHELL, C. A Effects of mechanical stress or abscisic acid on growth, water status and leaf abscisic acid content of eggplant seedlings. Scientia Horticulturae, v. 36, n. 1/2, p.37-46, July 1988. 
LATIMER, J. G.; JOHJIMA, T.; HARADA, K. The effect of mechanical stress on transplant growth and subsequent yield of four cultivars of cucumber. Scientia Horticulturae, v. 47, n. 3/4, p.221-30, July 1991.

LATIMER, J. G.; PAPPAS, T.; MITCHELL, C. A. Growth responses of eggplant and soybean seedlings to mechanical stress in greenhouse and outdoor enviromments. Journal of the American Society for Horticultural Science, v. 111, n. 5, p. 694-8, Sept. 1986.

LIPTAY, A Reduction od spindliness of tomato transplants grown at high densities. Canadian Journal of Plant Science, v. 65, p. 797 - 801, July 1985.

MCKEE, J.M.T. Physiological aspects of transplanting vegetables and other crops. Horticultural Abstracts, v. 51, n. 5, p. 265-72, May 1981.

MINAMI, K.; HAAG, H. P. O tomateiro. 2.ed. Campinas: Fundação Cargill, 1989. p. 10-8: a planta.

MITCHELL, C. A Influence of mechanical stress on auxin-stimulated growth of excised pea stem sections. Physiology Plantarum, v. 41, n. 2, p. 129 -34, Oct. 1977.

MITCHELL, C. A Recent advances in plant response to mechanical stress: theory and application. HortScience, v. 31, n. 1, p. 31-5, Feb. 1996.

MITCHELL, C. A; DOSTAL, H.C.; SEIPEL, T. M. Dry weight reduction in mechanically-dwarfed tomato plants. Journal of the American Society for Horticultural Science, v. 102, n. 5, p. 605-8, Sept. 1977. 
MITCHELL, C. A; SEVERSON, C. J.; WOTT, J. A; HAMMER, P. A Seismomorphogenic regulation of plant growth. Journal of the American Society for Horticultural Science, v. 100, n. 2, p. 161-5, Jan. 1975.

NEEL, P.L.; HARRIS, R.W. Tree seedling growth: effects of skaking. Sclence, v. 175, p. 918-9, Feb. 1972.

NARAYANA, I.; LALONDE, S.; SAINI, H.S. Water-stress-induced ethylene production in wheat (A fact or artfact?). Plant Physiology, v. 96, n. 2, p. 406-10, June 1991.

PAPPAS, T.; MITCHELL, C.A. Influence of seismic stress on photosynthetic productivity, gas exchange, and leaf diffusive resistance of Glycine max (L.) Merril cv Wells II. Plant Physiology, v. 79, p. 285-9, Sept. 1985.

PARDOSSI, A; TOGNONI, F; LOVEMORE, S. S. The effect of different hardening treatments on tomato seedling growth, chilling resistance and crop production in cold greenhouse. Acta Horticulturae, v. 229, p. 371 - 8, Dec. 1988.

REYES, E.; JENNINGS, P. H. Response of cucumber (Cucumis sativus L.) and squash (Cucurbita pepo L. var. melopepo) roots to chilling stress during early stages of seedling development. Journal of the American Society for Horticultural Science, v. 119, n. 5, p. 964 - 70, Sept. 1994.

RIAZI, A; MATSUDA, K.; ARSLAN, A Water-stress induced changes in concentrations of proline and other solutes in growing regions of young barley leaves. Journal of Experimental Botany, v. 36, n. 172, p. 1716-25, Nov. 1985. 
SHAWISH, O; BAKER, R. Thigmomorphogenesis and predisposition of hosts to fusarium wilt. Phytopathology, v. 72, n. 1, p. 63-8, Jan. 1982.

WURR, D.C.E.; FELLOWS, J. R.; HADLEY, P. The influence of supplementary lighting and mechanically-induced stress during plant raising, on transplant and maturity characteristics of crisp lettuce. Journal of Horticultural Science, v. 61, n. 3, p. $325-30$, July 1986.

ZONTA, E.P.; MACHADO, AA. Sistema de Análise Estatistica - SANEST. (Software). Piracicaba: USP, CIAGRI, 1996. Disquete. 


\section{APÊNDICE}

Nas Tabelas 22 a 26 são apresentados os dados climatológicos: precipitação em milimetros, velocidade do vento em quilômetros/hora; temperaturas máxima, mínima e média em graus centígrados, a evaporação em milimetros, diários, de acordo com o Departamento de Física e Metereolugia da ESALQ.

Tabela 22. Dados climatológicos referentes ao mês de Julho/95

\begin{tabular}{ccccccc}
\hline DIA & Precipitação & Ventokm/h & TempMáx. & TempMin. & TempMed & Evaporação \\
\hline 01 & 0,00 & 7,10 & 26,80 & 10,4 & 18,60 & 3,06 \\
02 & 0,00 & 6,70 & 28,50 & 11,0 & 19,75 & 2,86 \\
03 & 0,00 & 5,70 & 28,40 & 13,0 & 20,70 & 3,40 \\
04 & 0,00 & 8,80 & 26,30 & 13,30 & 19,80 & 3,54 \\
05 & 0,00 & 9,30 & 28,30 & 11,50 & 19,90 & 3,33 \\
06 & 0,00 & 11,0 & 29,00 & 15,60 & 22,30 & 3,61 \\
07 & 0,50 & 7,30 & 29,50 & 15,90 & 22,70 & 4,30 \\
08 & 7,20 & 7,00 & 16,70 & 13,80 & 15,25 & 0,24 \\
09 & 44,10 & 4,50 & 17,40 & 14,70 & 16,05 & 2,94 \\
10 & 1,00 & 5,50 & 22,70 & 15,20 & 18,95 & 0,89 \\
11 & 0,00 & 5,10 & 25,20 & 10,00 & 17,60 & 2,37 \\
12 & 0,00 & 7,00 & 27,10 & 10,20 & 18,65 & 2,97 \\
13 & 0,00 & 7,50 & 28,70 & 11,10 & 19,90 & 1,75 \\
14 & 0,00 & 6,30 & 29,00 & 12,00 & 20,50 & 4,17 \\
15 & 0,00 & 6,10 & 28,20 & 15,00 & 21,60 & 2,11 \\
16 & 0,00 & 5,80 & 28,80 & 17,60 & 23,20 & 2,72 \\
17 & 0,00 & 6,00 & 29,30 & 14,40 & 21,85 & 3,08 \\
18 & 0,00 & 8,30 & 26,70 & 14,10 & 20,40 & 3,52 \\
19 & 0,00 & 10,10 & 28,00 & 12,00 & 20,00 & 4,28 \\
20 & 0,40 & 9,30 & 20,40 & 17,90 & 19,15 & 1,78 \\
21 & 5,90 & 8,70 & 21,2 & 11,20 & 16,20 & 1,72 \\
22 & 0,00 & 5,30 & 20,2 & 11,0 & 15,60 & 1,28 \\
23 & 0,00 & 5,10 & 25,1 & 7,70 & 16,40 & 2,28 \\
24 & 0,00 & 6,80 & 29,3 & 9,70 & 19,50 & 3,32 \\
25 & 0,00 & 7,30 & 29,6 & 11,10 & 20,35 & 3,96 \\
26 & 0,00 & 7,40 & 29,40 & 12,60 & 21,00 & 3,72 \\
27 & 0,00 & 7,80 & 29,50 & 12,00 & 20,75 & 3,39 \\
28 & 0,00 & 9,10 & 29,70 & 15,10 & 22,40 & 6,13 \\
29 & 0,00 & 8,00 & 31,00 & 14,80 & 22,90 & 4,60 \\
30 & 0,00 & 7,20 & 30,00 & 12,90 & 21,45 & 2,40 \\
31 & 0,00 & 6,60 & 30,30 & 12,30 & 21,30 & 3,94 \\
\hline & & & & & &
\end{tabular}


Tabela 23. Dados climatológicos referentes ao mês de Agosto/95

\begin{tabular}{ccccccc}
\hline DIA & Precipitação & Ventokm/h & TempMáx & TempMin & TempMed & Evaporação \\
\hline 01 & 0,00 & 8,10 & 29,20 & 12,40 & 20,80 & 5,10 \\
02 & 0,00 & 8,20 & 29,40 & 10,30 & 19,85 & 4,66 \\
03 & 0,00 & 7,90 & 31,50 & 13,00 & 22,25 & 3,14 \\
04 & 0,90 & 12,6 & 23,40 & 14,90 & 19,15 & 5,08 \\
05 & 0,30 & 10,3 & 16,80 & 13,50 & 15,15 & 1,92 \\
06 & 0,00 & 8,20 & 23,80 & 12,00 & 17,90 & 2,76 \\
07 & 0,00 & 7,60 & 31,60 & 12,50 & 22,05 & 4,04 \\
08 & 0,00 & 6,80 & 32,00 & 16,30 & 24,15 & 4,16 \\
09 & 0,00 & 9,60 & 31,40 & 15,70 & 23,55 & 5,22 \\
10 & 0,00 & 6,80 & 31,90 & 14,60 & 23,25 & 4,49 \\
11 & 0,00 & 6,70 & 31,30 & 13,00 & 22,15 & 5,02 \\
12 & 0,00 & 9,40 & 32,30 & 13,20 & 22,75 & 5,14 \\
13 & 0,00 & 7,00 & 32,60 & 13,40 & 23,00 & 4,56 \\
14 & 0,00 & 9,20 & 33,30 & 11,90 & 22,60 & 5,98 \\
15 & 0,00 & 9,80 & 32,60 & 12,80 & 22,70 & 6,46 \\
16 & 0,00 & 10,00 & 32,00 & 13,60 & 22,80 & 3,41 \\
17 & 0,00 & 11,70 & 28,30 & 14,60 & 21,45 & 4,42 \\
18 & 0,00 & 6,90 & 30,60 & 12,40 & 21,50 & 5,46 \\
19 & 0,00 & 12,00 & 26,40 & 14,40 & 20,40 & 5,76 \\
20 & 0,00 & 9,20 & 27,40 & 12,60 & 20,00 & 4,48 \\
21 & 0,00 & 5,50 & 29,40 & 11,10 & 20,25 & 4,16 \\
22 & 0,00 & 6,40 & 30,40 & 12,60 & 21,50 & 3,80 \\
23 & 0,00 & 6,10 & 31,10 & 12,80 & 21,95 & 5,60 \\
24 & 0,00 & 7,00 & 31,50 & 13,20 & 22,35 & 5,88 \\
25 & 0,00 & 7,60 & 31,60 & 10,80 & 21,20 & 5,90 \\
26 & 0,00 & 7,00 & 31,50 & 10,80 & 21,15 & 5,54 \\
27 & 0,00 & 8,00 & 32,50 & 12,50 & 22,50 & 6,08 \\
28 & 0,00 & 6,50 & 32,60 & 13,00 & 22,80 & 3,61 \\
29 & 0,00 & 6,10 & 33,60 & 14,10 & 23,85 & 6,11 \\
30 & 0,00 & 7,60 & 34,50 & 12,80 & 23,65 & 6,90 \\
31 & 0,00 & 12,10 & 34,30 & 13,60 & 23,95 & 5,60 \\
\hline
\end{tabular}


Tabela 24. Dados climatológicos referentes ao mês de Setembro/95

\begin{tabular}{ccccccc}
\hline DIA & Precipitação & Ventokm/h & TempMáx. & TempMin. & TempMed. & Evaporação \\
\hline 01 & 0,00 & 7,00 & 34,80 & 13,00 & 23,90 & 7,76 \\
02 & 0,00 & 10,50 & 33,70 & 14,20 & 23,95 & 6,58 \\
03 & 0,00 & 18,20 & 26,70 & 14,70 & 20,70 & 5,66 \\
04 & 0,00 & 15,00 & 25,80 & 15,00 & 20,40 & 5,76 \\
05 & 0,00 & 8,50 & 26,90 & 8,90 & 17,90 & 6,12 \\
06 & 0,00 & 6,50 & 29,20 & 8,20 & 18,70 & 6,06 \\
07 & 0,00 & 6,60 & 30,20 & 9,40 & 19,80 & 5,78 \\
08 & 0,00 & 6,70 & 32,20 & 9,90 & 21,05 & 5,98 \\
09 & 0,00 & 6,10 & 33,60 & 10,40 & 22,00 & 6,28 \\
10 & 0,00 & 8,50 & 34,70 & 12,70 & 23,70 & 6,68 \\
11 & 0,00 & 6,40 & 35,50 & 13,90 & 24,70 & 7,26 \\
12 & 0,00 & 20,90 & 27,60 & 16,30 & 21,95 & 6,07 \\
13 & 0,00 & 7,30 & 28,40 & 15,20 & 21,80 & 3,97 \\
14 & 0,00 & 8,40 & 34,60 & 14,60 & 24,60 & 5,86 \\
15 & 0,00 & 13,20 & 30,20 & 19,40 & 24,80 & 6,31 \\
16 & 0,00 & 10,10 & 28,50 & 10,80 & 19,65 & 7,21 \\
17 & 3,50 & 8,40 & 23,80 & 11,40 & 17,60 & 1,94 \\
18 & 3,90 & 12,50 & 34,30 & 16,60 & 25,45 & 5,54 \\
19 & 5,50 & 13,80 & 30,50 & 18,70 & 24,60 & 6,56 \\
20 & 0,60 & 17,20 & 16,90 & 14,00 & 15,45 & 2,54 \\
21 & 0,00 & 17,90 & 20,60 & 12,90 & 16,75 & 3,50 \\
22 & 0,00 & 10,00 & 29,70 & 13,00 & 21,35 & 5,94 \\
23 & 4,60 & 10,90 & 23,60 & 15,40 & 19,50 & 2,15 \\
24 & 8,90 & 8,30 & 24,80 & 17,30 & 21,05 & 1,61 \\
25 & 0,00 & 11,10 & 27,80 & 16,80 & 22,30 & 4,06 \\
26 & 10,00 & 11,80 & 32,30 & 15,20 & 23,75 & 5,20 \\
27 & 0,30 & 10,30 & 25,60 & 16,00 & 20,80 & 2,86 \\
28 & 0,30 & 8,20 & 24,60 & 16,40 & 20,50 & 1,84 \\
29 & 0,00 & 7,90 & 26,60 & 15,20 & 20,90 & 3,58 \\
30 & 0,00 & 7,90 & 31,70 & 16,10 & 23,90 & 6,28 \\
\hline & & & & & &
\end{tabular}


Tabela 25. Dados climatológicos referentes ao mês de Outubro/95

\begin{tabular}{|c|c|c|c|c|c|c|}
\hline DIA & Precipitação & Ventolm $\mathrm{m} / \mathrm{h}$ & TempMáx. & TempMin. & TempMed. & Evaporação \\
\hline 01 & 0,00 & 9,50 & 32,60 & 16,90 & 24,75 & 6,50 \\
\hline 02 & 0,00 & 9,70 & 32,60 & 17,10 & 24,85 & 7,60 \\
\hline 03 & 0,00 & 11,30 & 30,80 & 16,60 & 23,70 & 8,13 \\
\hline 04 & 0,00 & 9,40 & 33,80 & 14,20 & 24,00 & 7,40 \\
\hline 05 & 8,70 & 13,20 & 29,60 & 15,90 & 22,75 & 7,40 \\
\hline 06 & 0,60 & 6,40 & 26,40 & 17,00 & 21,70 & 2,38 \\
\hline 07 & 0,00 & 8,10 & 31,30 & 15,50 & 23,40 & 6,22 \\
\hline 08 & 0,00 & 10,80 & 31,50 & 18,30 & 24,90 & 7,80 \\
\hline 09 & 0,00 & 7,70 & 28,50 & 18,70 & 23,60 & 2,38 \\
\hline 10 & 0,00 & 6,80 & 30,20 & 16,70 & 23,45 & 6,77 \\
\hline 11 & 0,00 & 8,30 & 30,60 & 12,30 & 21,45 & 7,06 \\
\hline 12 & 0,00 & 6,20 & 34,30 & 12,20 & 23,25 & 6,22 \\
\hline 13 & 39,00 & 10,40 & 28,00 & 17,80 & 22,90 & 5,62 \\
\hline 14 & 2,50 & 5,80 & 25,30 & 17,90 & 21,60 & 2,18 \\
\hline 15 & 12,90 & 2,90 & 21,70 & 19,20 & 20,45 & 0,50 \\
\hline 16 & 15,90 & 5,80 & 23,00 & 18,60 & 20,80 & 0,21 \\
\hline 17 & 18,20 & 7,90 & 19,00 & 17,50 & 18,25 & 1,57 \\
\hline 18 & 0,00 & 8,00 & 28,20 & 13,60 & 20,90 & 4,94 \\
\hline 19 & 23,40 & $12,80^{*}$ & 28,10 & 17,60 & 22,85 & \\
\hline 20 & 22,30 & $6,90 * *$ & 24,40 & 11,20 & 17,80 & \\
\hline 21 & 0,00 & 8,30 & 25,80 & 15,50 & 20,65 & 3,82 \\
\hline 22 & 0,00 & 13,40 & 25,30 & 13,30 & 19,30 & 8,48 \\
\hline 23 & 0,00 & 7,70 & 27,80 & 11,70 & 19,75 & 4,86 \\
\hline 24 & 0,00 & 8,90 & 33,20 & 12,50 & 22,85 & 7,52 \\
\hline 25 & 0,00 & 9,00 & 34,30 & 14,70 & 24,50 & 7,52 \\
\hline 26 & 0,00 & 8,20 & 34,90 & 16,20 & 25,55 & 7,44 \\
\hline 27 & 0,00 & 9,60 & 35,20 & 17,40 & 26,30 & 8,56 \\
\hline 28 & 10,60 & 10,70 & 26,30 & 19,30 & 22,80 & 3,82 . \\
\hline 29 & 22,00 & 22,50 & 21,30 & 15,80 & 18,55 & 2,02 \\
\hline 30 & 13,10 & 19,50 & 21,80 & 13,50 & 17,65 & 4,89 \\
\hline 31 & 1,00 & 13,50 & 22,70 & 14,70 & 18,70 & 3,13 \\
\hline
\end{tabular}

* Velocidade máxima registrada $=126,72 \mathrm{~km} / \mathrm{hora}$.

** Velocidade máxima registrada $=77,76 \mathrm{~km} /$ hora. 
Tabela 26. Dados climatológicos referentes ao mês de Novembro/95

\begin{tabular}{ccccccc}
\hline DIA & Precipitação & Ventokm/h & TempMáx. & TempMin. & TempMed. & Evaporação \\
\hline 01 & 0,00 & 14,80 & 26,50 & 14,50 & 20,50 & 5,32 \\
02 & 3,40 & 9,50 & 29,20 & 16,10 & 22,65 & 5,85 \\
03 & 9,50 & 8,30 & 29,60 & 15,90 & 22,75 & 6,01 \\
04 & 0,00 & 8,80 & 27,00 & 17,50 & 22,25 & 3,87 \\
05 & 0,00 & 7,10 & 30,20 & 15,00 & 22,60 & 4,85 \\
06 & 0,00 & 7,80 & 32,30 & 16,90 & 24,60 & 6,44 \\
07 & 0,00 & 7,40 & 33,60 & 19,00 & 26,30 & 7,69 \\
08 & 0,00 & 6,80 & 35,50 & 19,40 & 27,45 & 7,72 \\
09 & 0,30 & 8,00 & 34,60 & 20,30 & 27,45 & 7,95 \\
10 & 4,70 & 11,90 & 34,30 & 21,90 & 28,10 & 8,33 \\
11 & 57,20 & 12,90 & 30,20 & 20,80 & 25,50 & \\
12 & 5,10 & 9,00 & 23,20 & 18,70 & 20,95 & 1,44 \\
13 & 0,00 & 8,80 & 25,50 & 17,30 & 21,40 & 2,66 \\
14 & 32,20 & 8,60 & 26,80 & 17,40 & 22,10 & 5,74 \\
15 & 0,00 & 8,80 & 28,70 & 19,50 & 24,10 & 4,44 \\
16 & 0,00 & 6,70 & 29,40 & 17,90 & 23,65 & 5,62 \\
17 & 0,00 & 9,30 & 32,20 & 18,10 & 25,15 & 8,76 \\
18 & 12,50 & 9,90 & 28,40 & 19,50 & 23,95 & 7,40 \\
19 & 0,00 & 12,80 & 27,30 & 14,50 & 20,90 & 6,97 \\
20 & 0,00 & 17,20 & 26,50 & 14,00 & 20,25 & 8,63 \\
21 & 0,00 & 11,50 & 28,80 & 13,70 & 21,25 & 8,13 \\
22 & 0,00 & 8,50 & 30,10 & 12,50 & 21,30 & 5,12 \\
23 & 0,00 & 6,80 & 31,40 & 15,40 & 23,40 & 4,06 \\
24 & 28,10 & 8,50 & 29,70 & 19,40 & 24,55 & \\
25 & 0,00 & 7,80 & 30,00 & 16,40 & 23,20 & 7,30 \\
26 & 0,00 & 6,40 & 33,30 & 16,60 & 24,95 & 7,36 \\
27 & 3,30 & 9,80 & 34,40 & 18,80 & 26,60 & 8,38 \\
28 & 0,00 & 15,50 & 28,90 & 19,20 & 24,05 & 7,69 \\
29 & 0,00 & 9,50 & 31,00 & 16,20 & 23,60 & 7,51 \\
30 & 0,00 & 7,80 & 33,90 & 16,00 & 24,95 & 7,36 \\
\hline & & & & & &
\end{tabular}

